
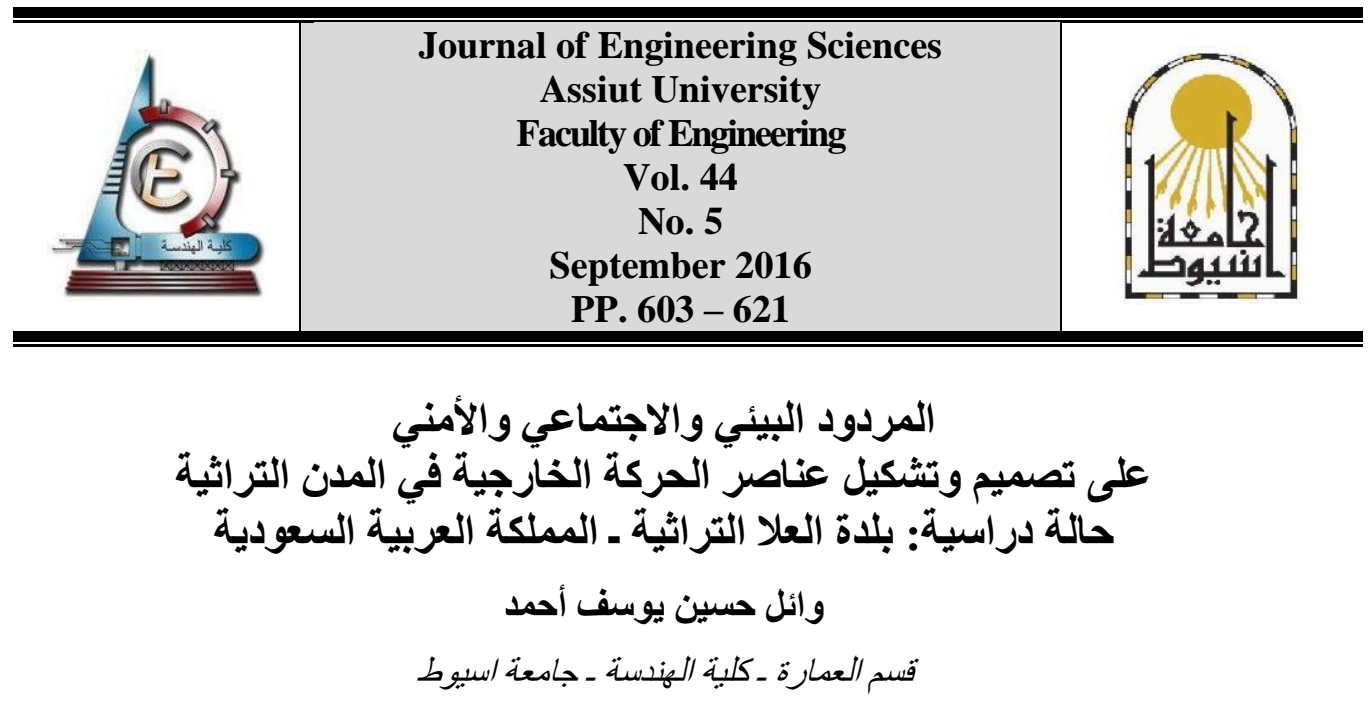

Received 13 June 2016; Accepted 18 July 2016

ملخص البحث

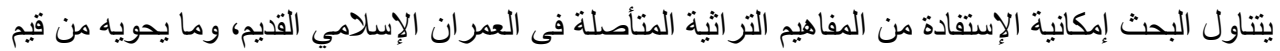

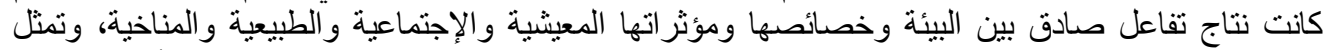

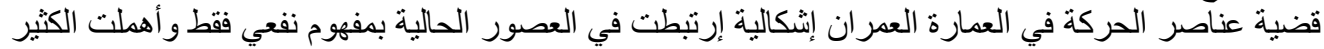

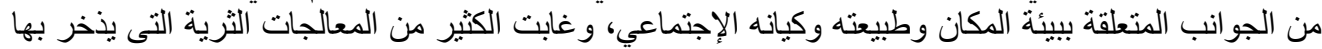

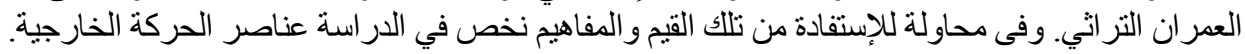

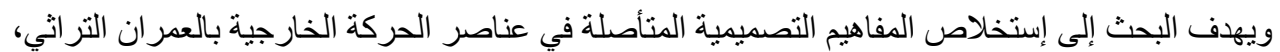

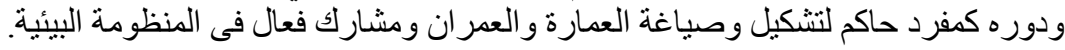

وتم إختيار بلدة العلا التراثية بالمملكة العربية السعودية كحالة در اسية، نم الحفاظ على غاليية عمر انها، تعبر

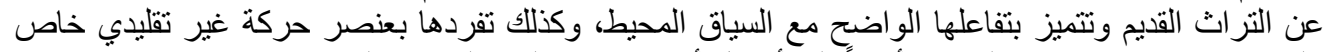

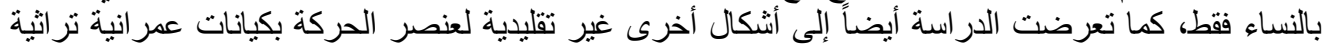
و اقعة في بيئات متفرقة الأماكن ومتثابهة التأثر و التفاعل بالمحتوى النقال المحيط.

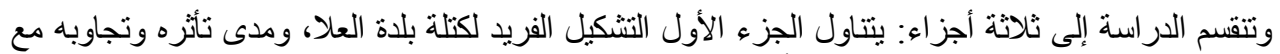

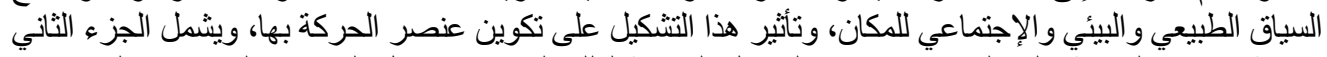

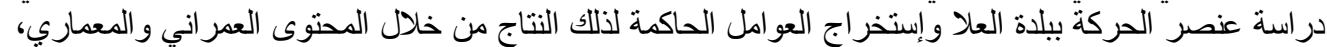

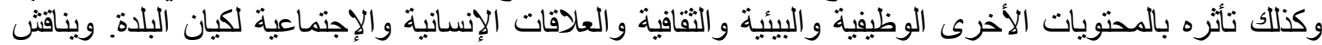
الجزء الثالث مفاهيم عناصر الحركة الخارجية غير التقلينية لأمثلة مشابهة في بلدات والعات وكيانات متفرقة. وتستخلص الدراسة النقاط و المفاهيم المهمة التى كان لها مردود فى صياغة عناصر الحركة الخارجية من نتاج تفاعلها التلقائي مع البيئة و المجنمع.

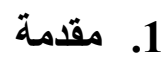

يتميز عنصر الحركة داخل المناطق التراثية بطبيعة خاصة، ففي معظم تلك المدن نتكل بصورة تلقائية وليدة

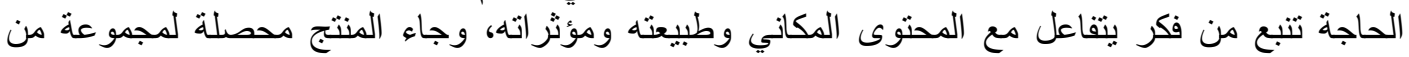

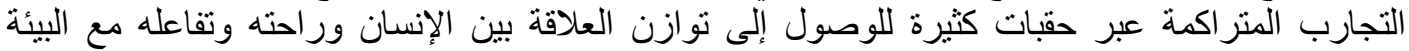

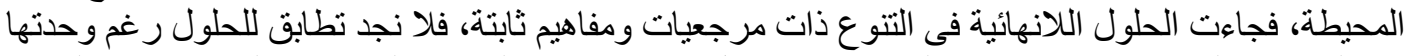

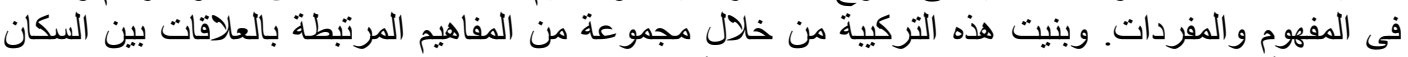

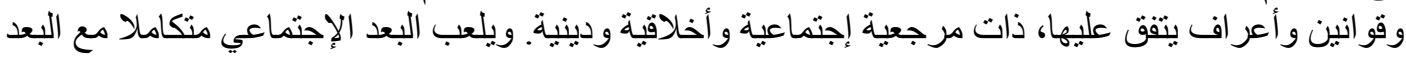


البيئي والأمني في هذه المناطق دوراً أساسياً في صياغة الحركة وتشكيلها وتحديد أنواعها و العلاقات الر ابطة بينها، وللخصوصية و المناخ أيضاً دوراً لايقل أهمية في فصل ورنياً وتشكيل وتحديد تللك الحركة.

وتمنل مدينة العلا حالة فريدة تميزت بها دون غير ها من المدن من حيث التركيبة العمر انية و التشكيلية، متمثلة في التئي

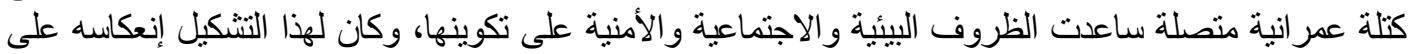

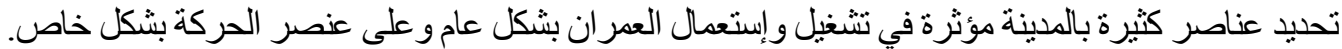

$$
\text { 1.1 إشكالبة البحث } 1.1
$$

تتمثل إثكالية البحث فى وجود الفارق الواضح بين استجابة وتفاعل عنصر الحركة في المدن للبيئة

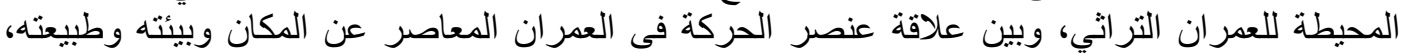

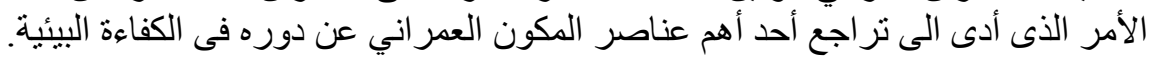

$$
\text { 1.2. هدف البحث }
$$

إستخلاص المفاهيم التصميمية المتأصلة لعناصر الحركة بالعمر ان التراثي، ودوره كمفرد حاكم لتشكيل وصياغة العمارة و العمر ان و مشارك فعال فى المنظومة البيئية و الإجتماعية والأمنية.

$$
\text { 1.3. منهج البحث }
$$

يعتمد البحث على المنهج التحليلي و الدر اسة الميدانية التوثيقية، وتم ذلك من خلال:

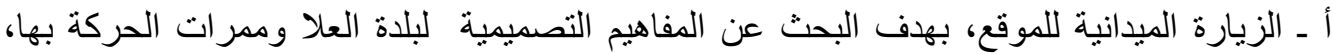

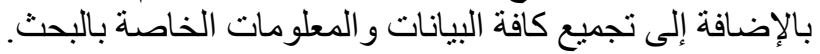

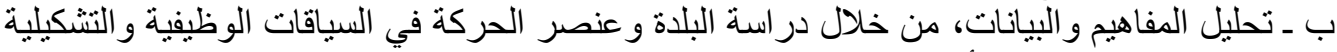
و البيئية والاجتماعية و الأمنية. ج - إستخلاص المردود البيئي والإجتماعي و المفاهيم التصميمية المتأصلة لعناصر الإنية الحركة بالعمران

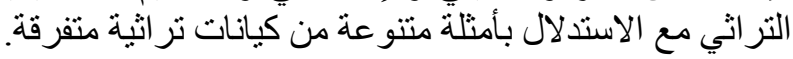

\section{2. تشكيل كتلة بلدة العلا وعلاقتها بعناصر الحركة}

شكلت بلدة العلا كتلة معمارية كبيرة مكونة من مجمو عة من المباني و البيوت المتر اكبة و المتلاصقة بحيث أنها

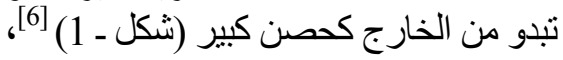

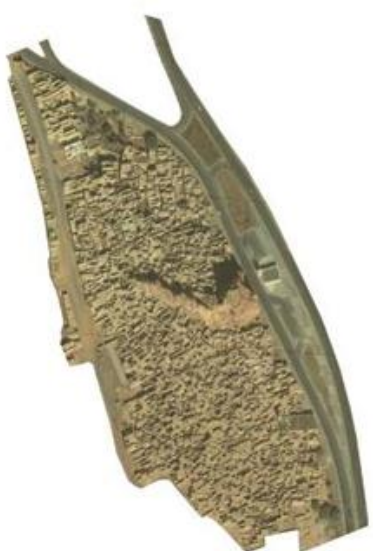

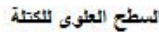

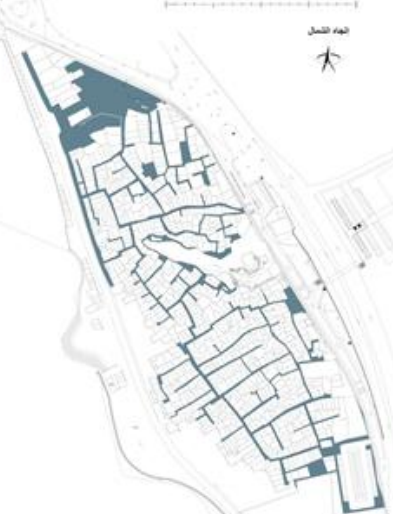

شكل المرات من أسقل

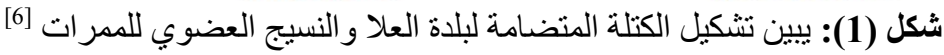


وائل حسين يوسف أحدد، المردود البيئي والاجتماعي والأمني على تصمبي وتثكبل عناصر الحركة الخارجية في الددن.

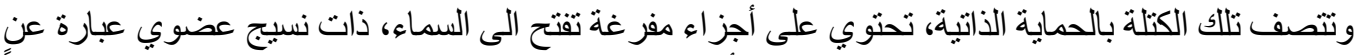

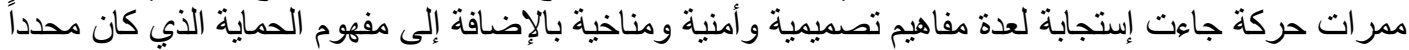

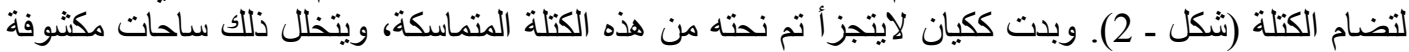

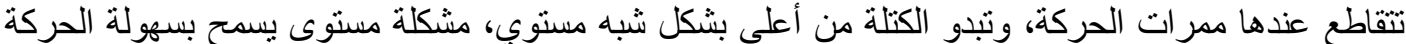

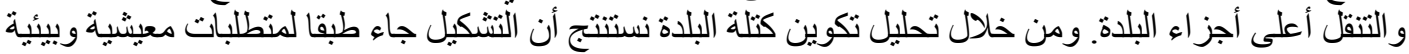

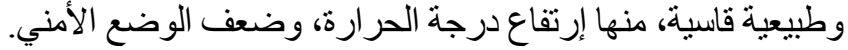

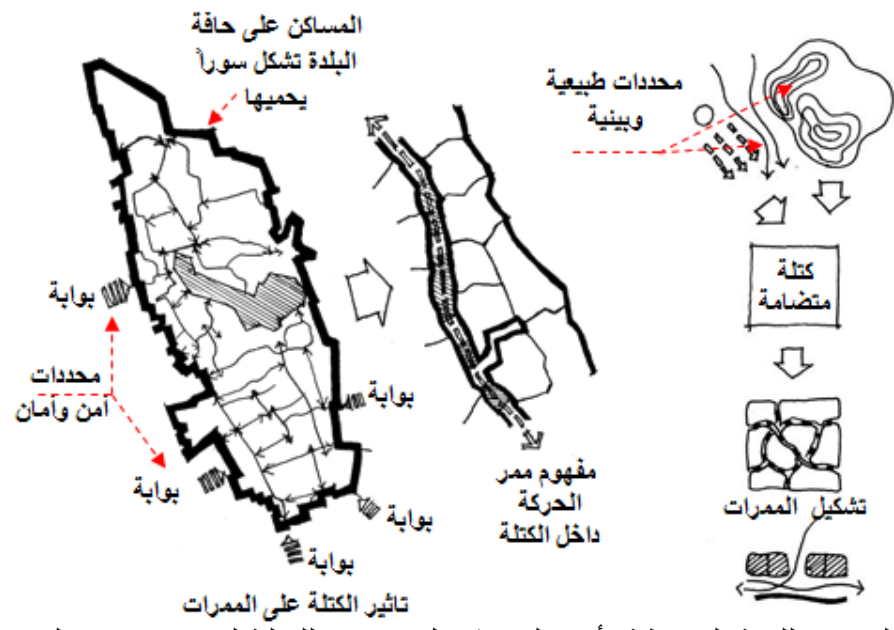

شكل (2): إستجابة العمر ان للبيئة المحيطة، أدى الى تشكيل منضـام للكتلة ليحقق مفهوم الحمايـة المنعكس بدوره على عناصر الحركة [10]

وكان للمبادئ الدينية و العادات و التقاليد الإجتماعية دوراً هاماً في صياغة تكوين البلدة والملامح التشكيلية

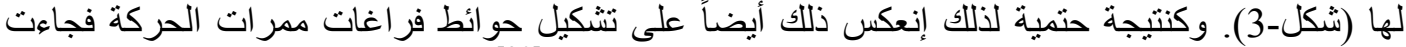
منحنية ومتعرجة لطبيعة المكان وبساطة وتلقائية البناء ومو اد البناء [20]
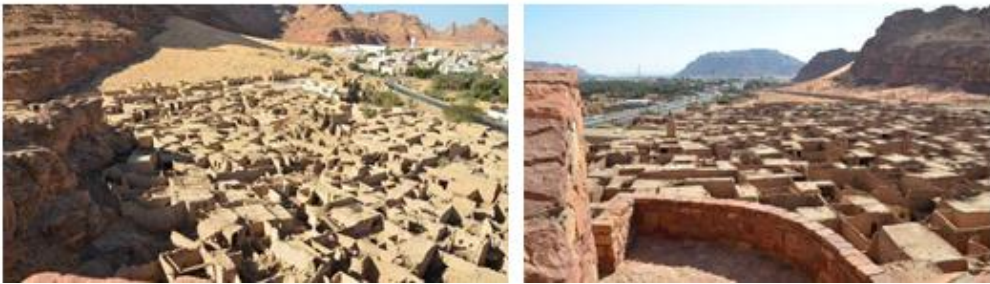

شكل (3): الملامح التشكيلية لبلدة العلا [10]

$$
\text { 1.2. بلدة العلا في السباق الطبيعي والبيئي. }
$$

نظراً لأن عنصر الحركة جزء من هذا الكيان الكلي، فقد كان من الضروري معرفة علاقة هذا الكيان بالسياق

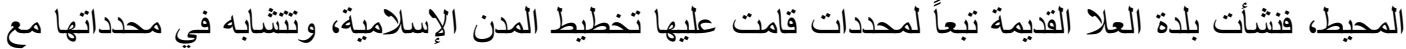

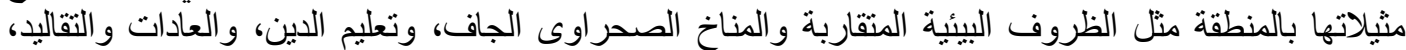

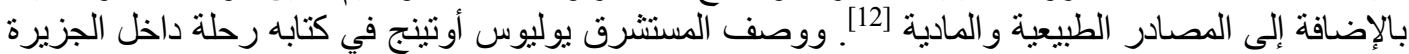

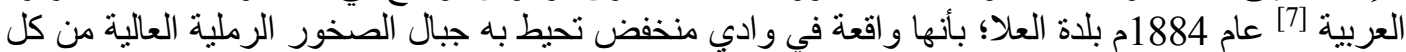

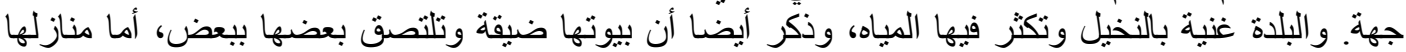

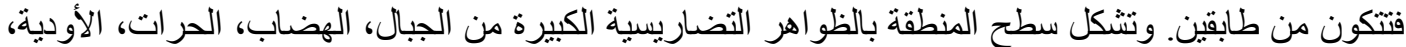

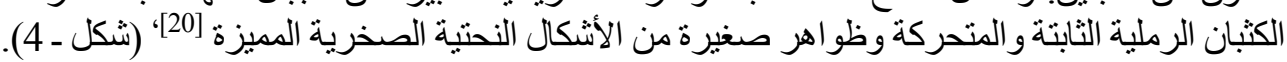




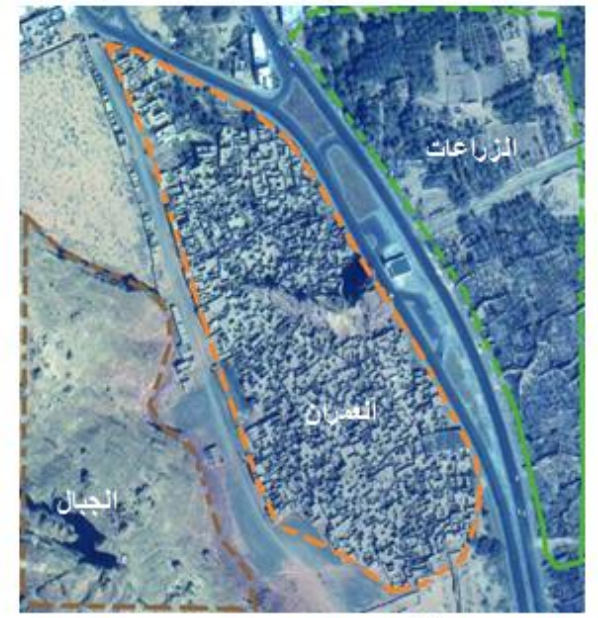

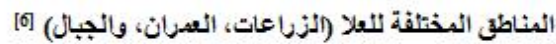

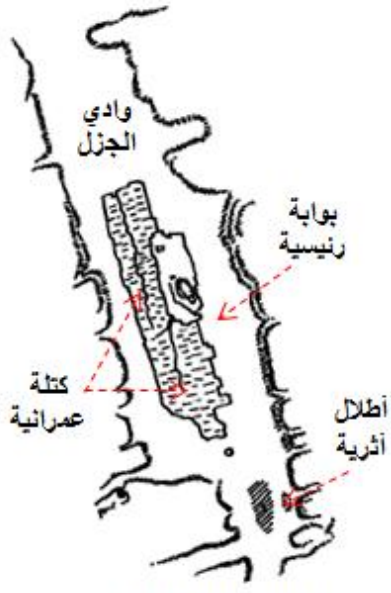

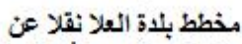

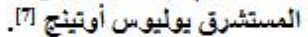
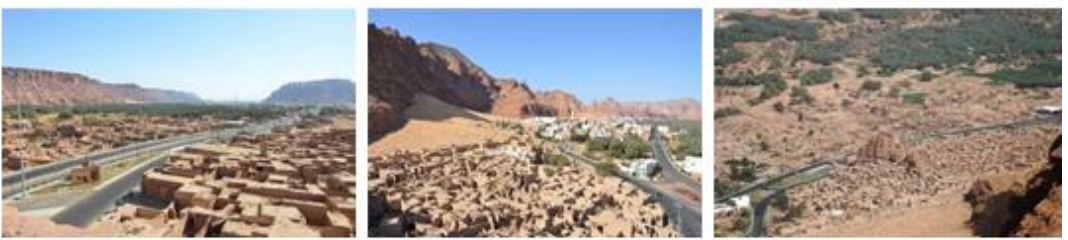

واقع بلدة العلا في عام 2014م [10].

شكل (4): المظاهر الطبيعية والعمر انية لبلدة العلا.

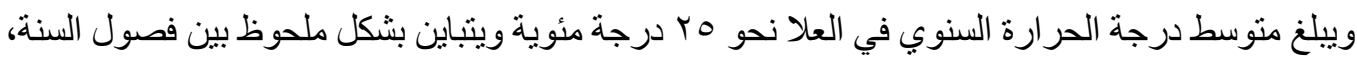

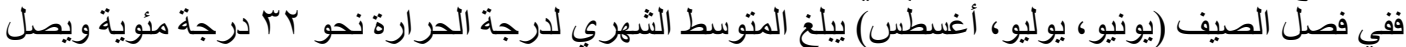

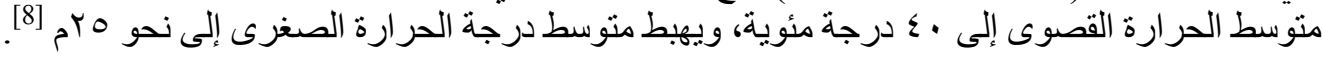

وفي تو افق مع هذا السياق نشأت العلا القديمة والتي بطلق عليها (الديرة) في الجزء الغربي من و ادي العلا، تحت جبل شاهق عالي الإرتفاع يقع في جهنها الغربية، ويفصل بينها وبين هذا الجبل ساحة مستطيلة تسمى الدور (المناخة)،

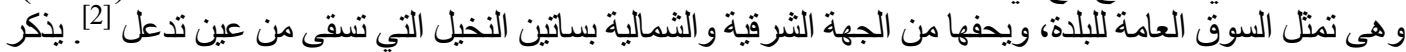

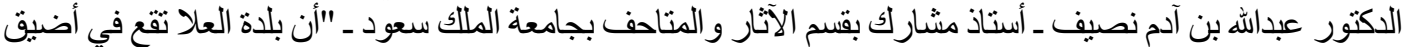
نقطة بالو ادي وقد بنيت منازل المرحلة الأولى فوق عنبة الهضبة الثنمالية بصفة عامة للإحتماء من مداهمات الهات السبول

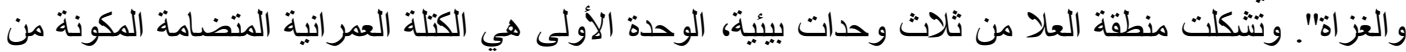

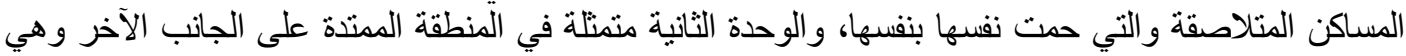

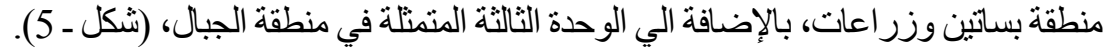

$$
\text { 2.2. مكونات بلدة العلا و عناصر الحركة }
$$

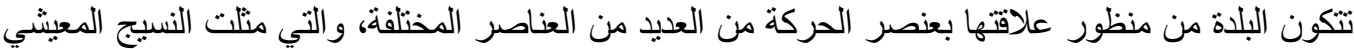

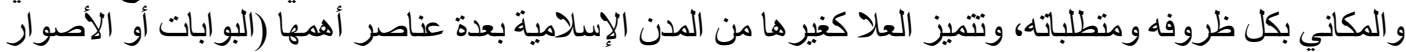

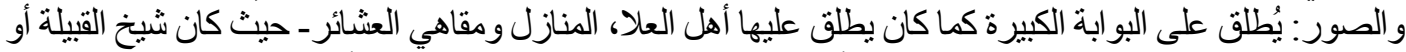

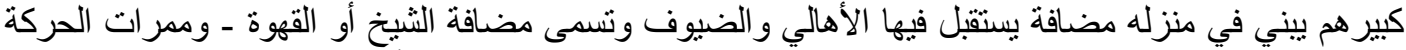

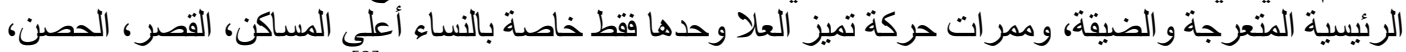

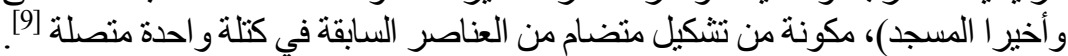



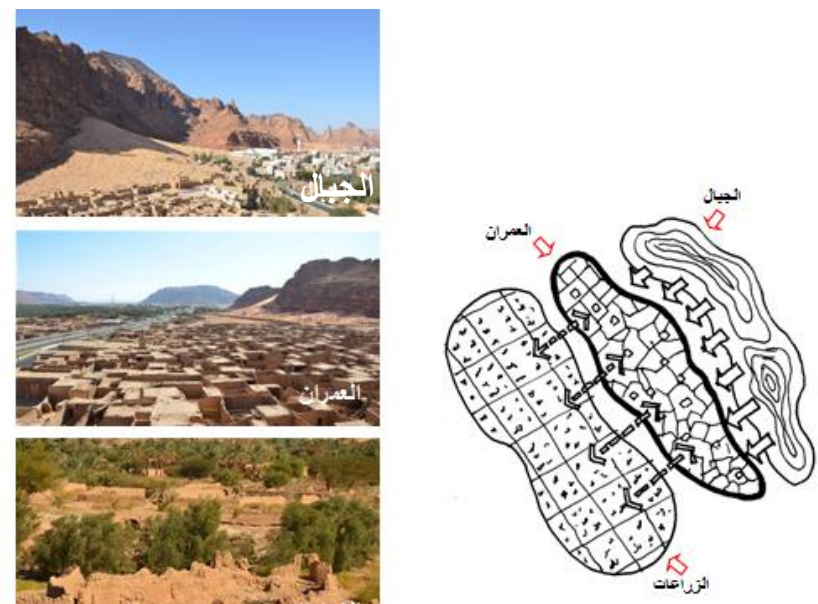

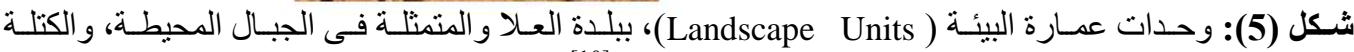

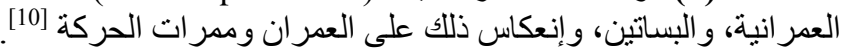

وقد نشأت بلدة العلا القيمة بعناصرها المختلفة وفق خطط بنائية أمنية تحترم الخصوصية منأثزة بالطبيعة و البيئة

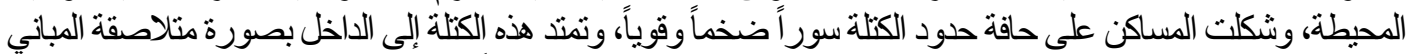

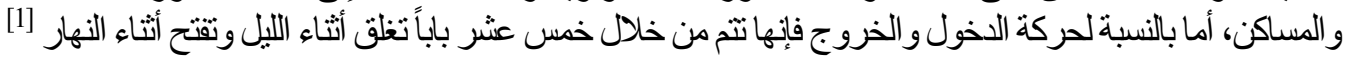

\section{3ـ عنصر الحركة بالعلا التراثية واستجابته للنطاق المحيط}

تمثل شوارع وطرق المدينة أهم جو انب تخطيطها والذي يعني تنسيق النظام المادي الطبيعي للمدينة، و إذا

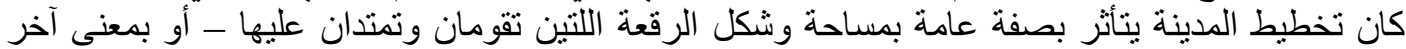

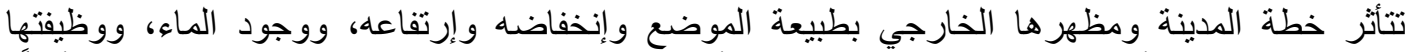

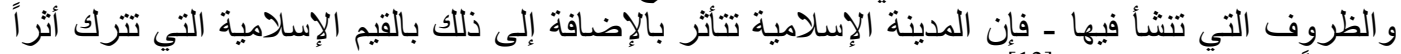

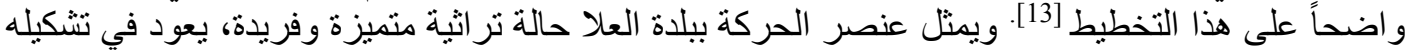

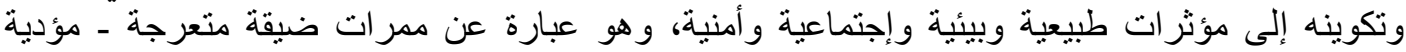

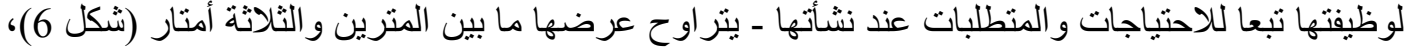

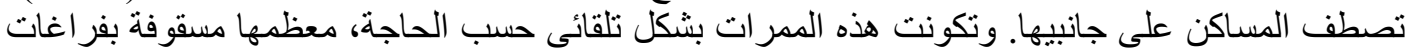
تعلو ها تخص المساكن، ويتحكم فى بداية ونهاية هذه الممر ات بون ابات أمنات أمنية لحمايتها.
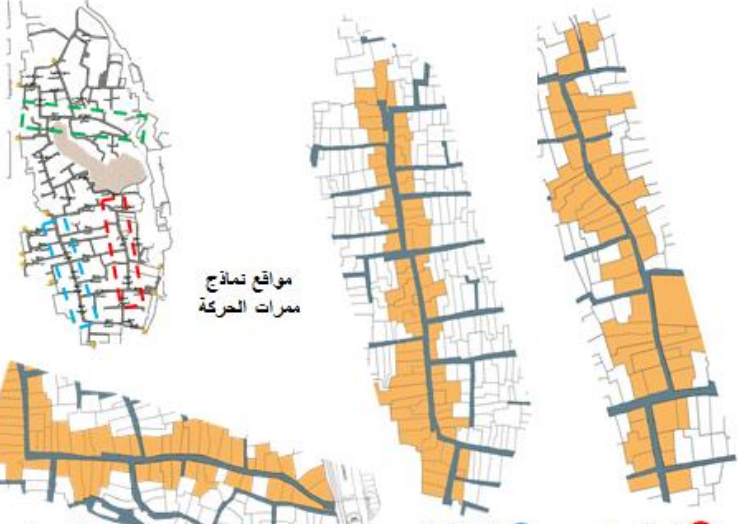

3 نون 3

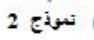

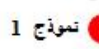

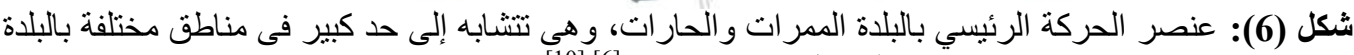

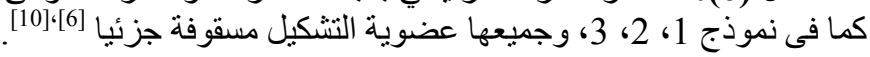




$$
\text { 1.3. أنواع الحركة ومكوناتها }
$$

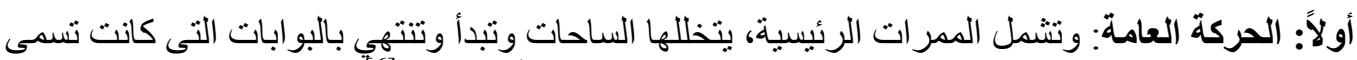

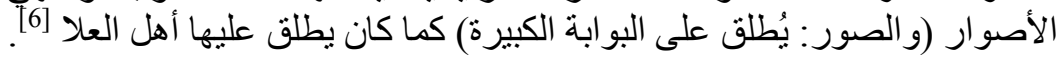

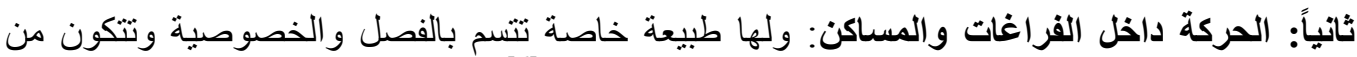

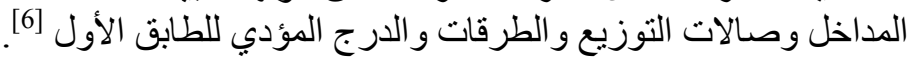

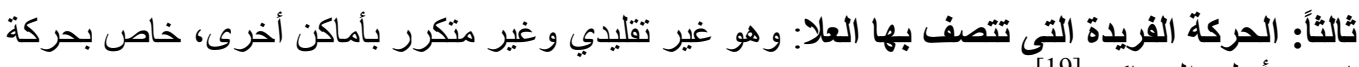

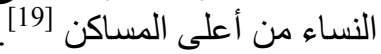
وتركز الدر اسة بالتفصيل على الحركة الخارجية ومايخصها من الحركة داخل السساكن.

$$
\text { 2.3. عنصر الحركة في السباق العمراني }
$$

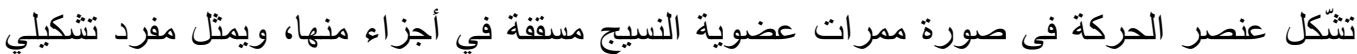

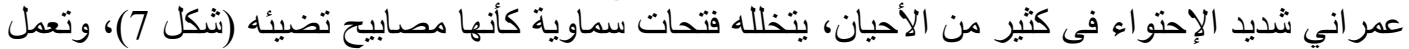

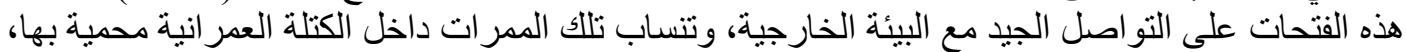

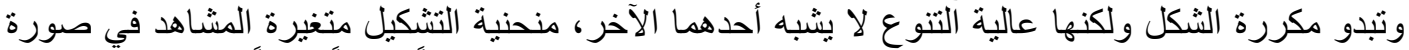

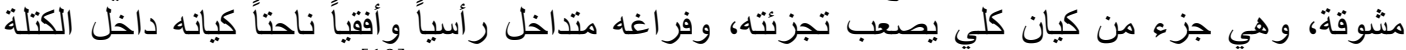

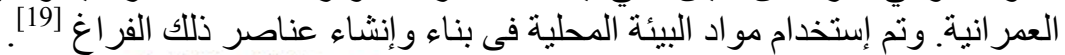

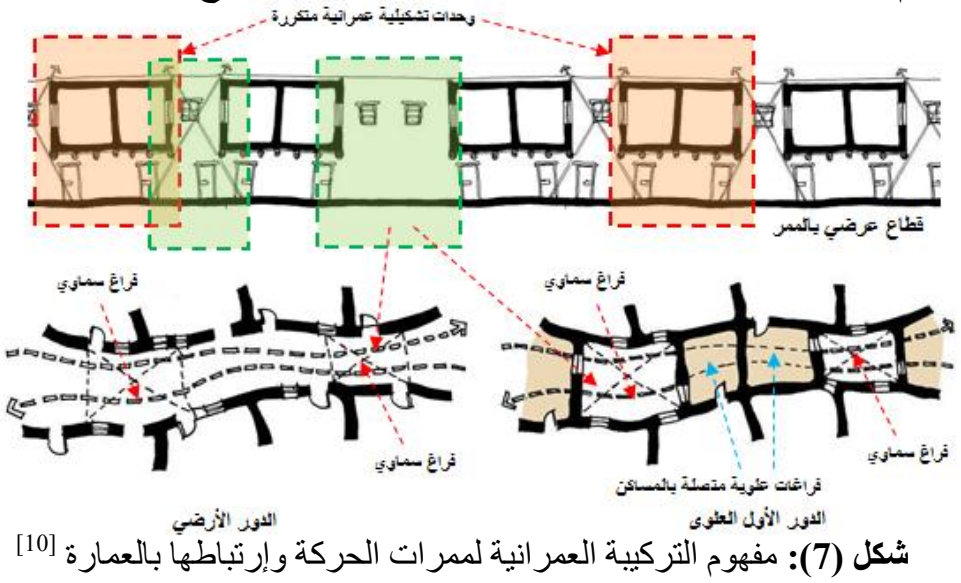

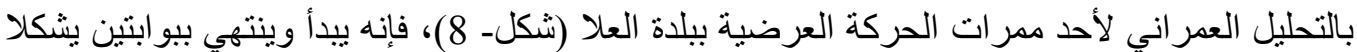

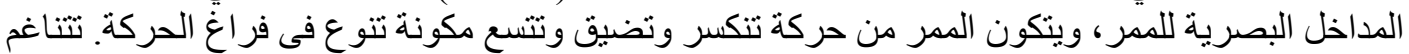

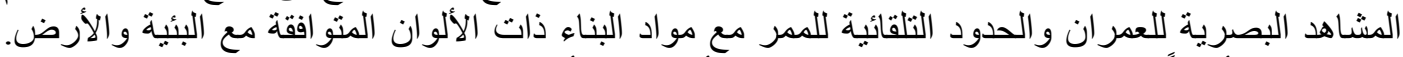

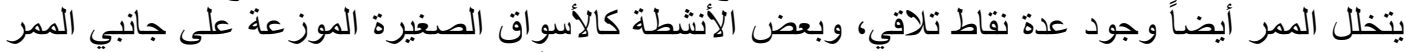

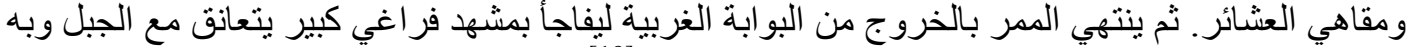
العديد من الأسواق المتر اصنة و الساحات المطلة ناحية الجبل [19.

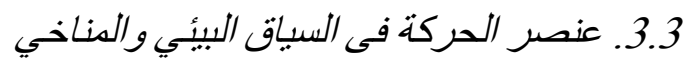

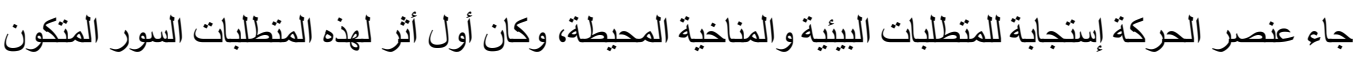

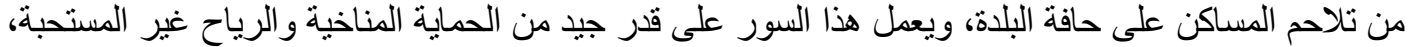

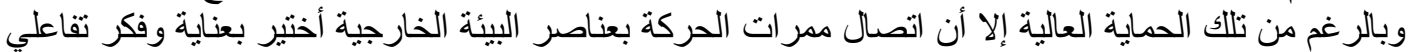

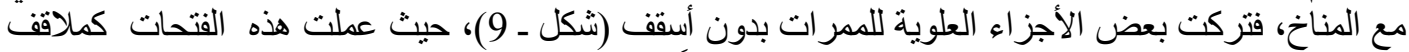
للهواء من كافة الاتجاهات، وإعتمدت حركة الهواء أيضاً على نظرية صعود الهواء الساخن إلى أعلى من خلال كلى 
وائل حسين يوسف أحدد، المردود البيئي والاجتماعي والأمني على تصديم وتثكيل عناصر الحركة الذارجية في الددن.

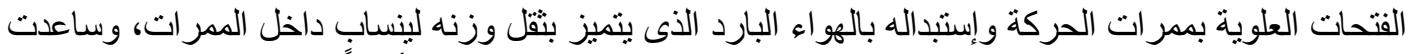

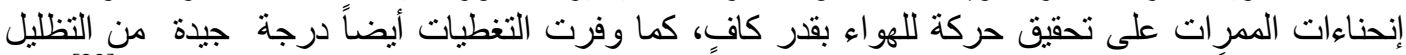

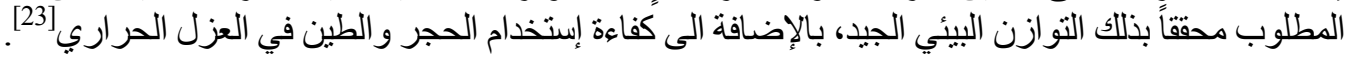

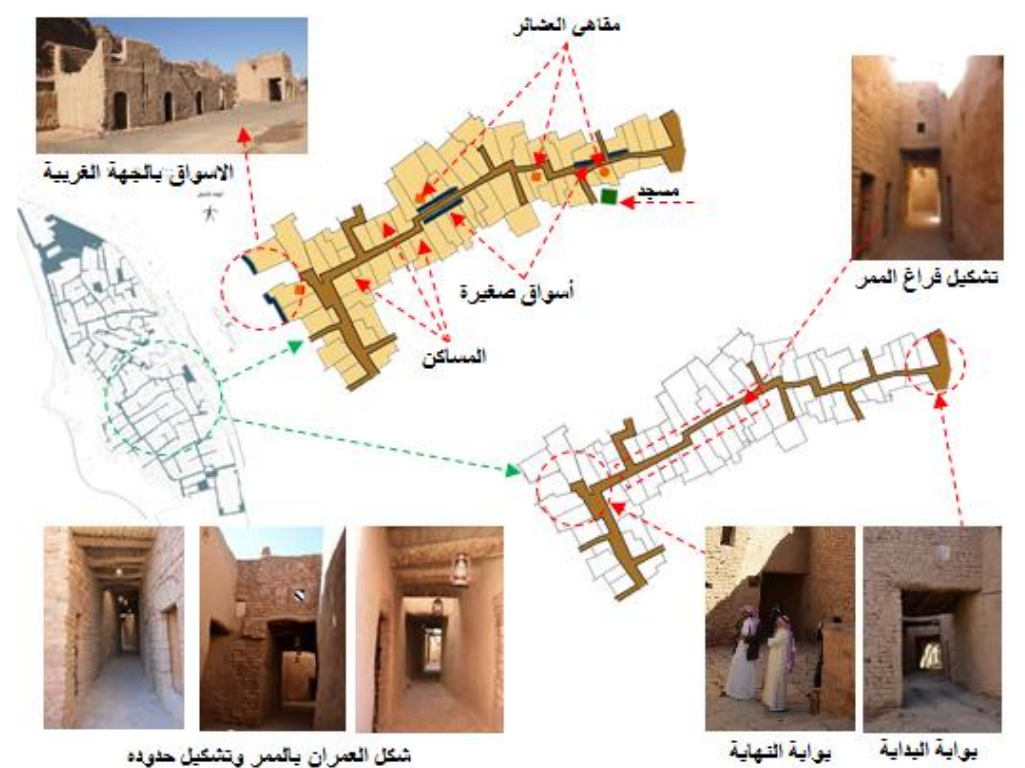

شكل (8): تحليل التركيبة العمر انية لأحد الممرات بيلدة العلا. [10ة

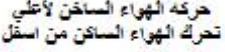

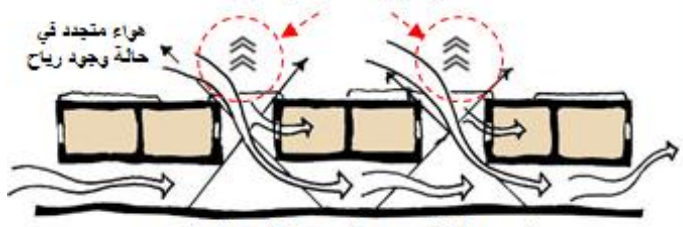

الثتريز باكتيلة يساتد تئى دخول الهواء إلى الممرات

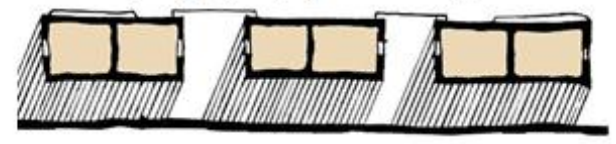

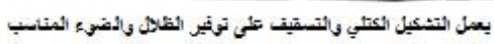

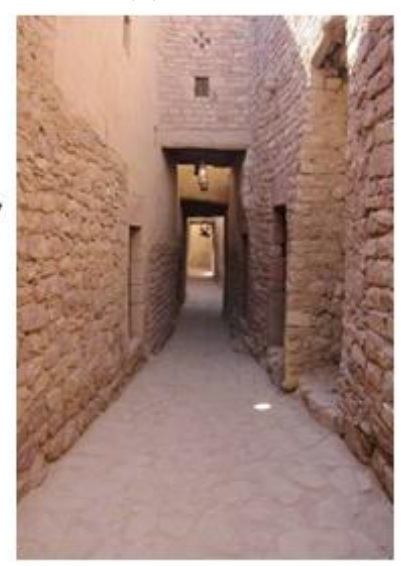

شكل (9): تشكيل ممر ات الحركة، عمل على تحريك الهو اء، ونوفير الظلال وقدر مناسب من الإضاءة [10]

ودن المؤثرات الطبيعية والبيئية على تكوين ممرات الحركة أنهاوجهت في غالبيتها من الغرب الى الثرات الثرق (شكل-

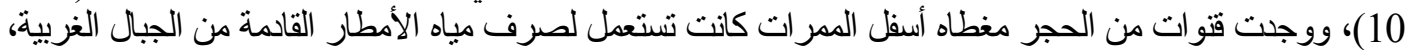

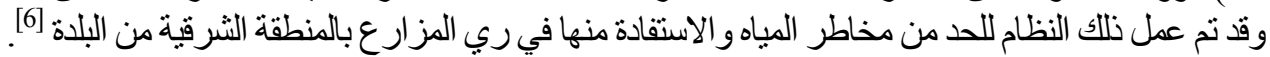



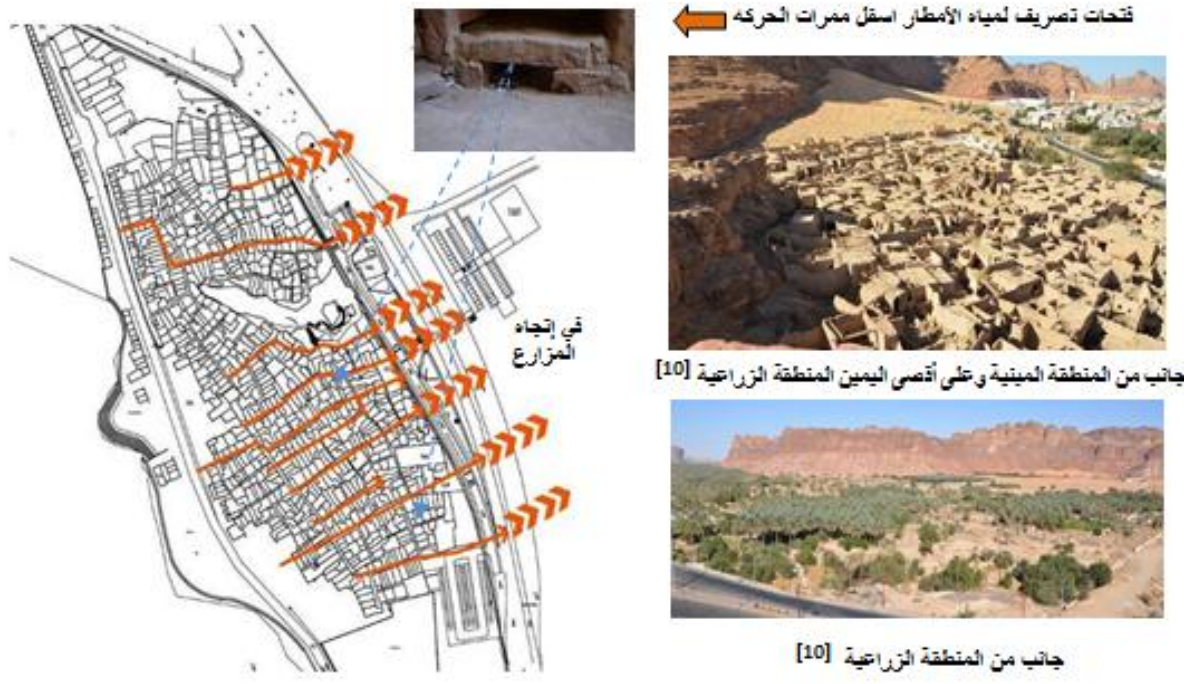

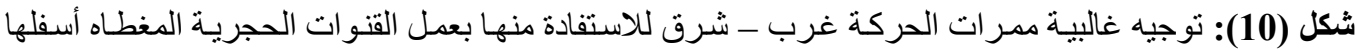

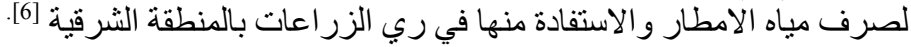

$$
\text { 4.3. عنصر الحركة فى السياق الوظيفي. }
$$

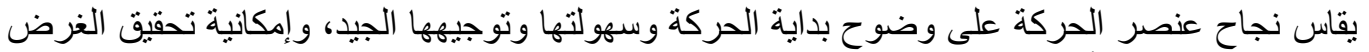

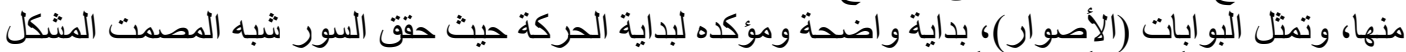

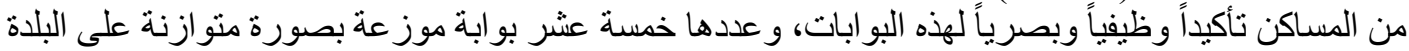

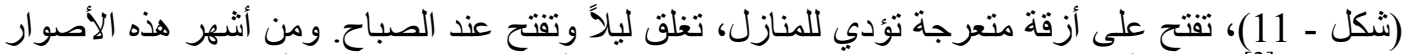

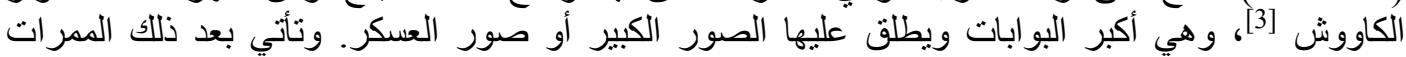

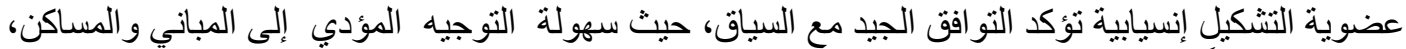

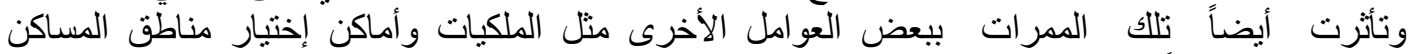

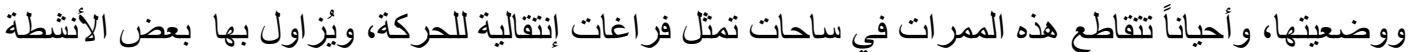

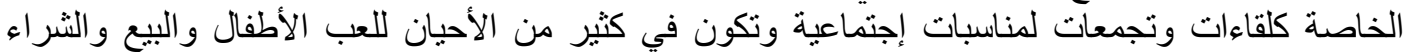

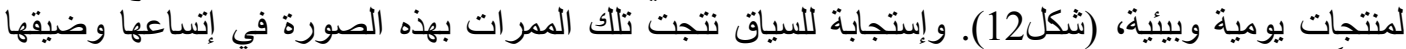

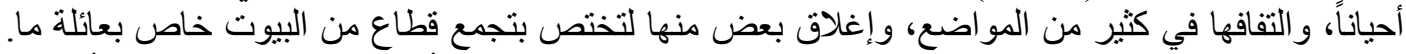

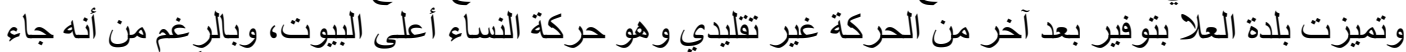

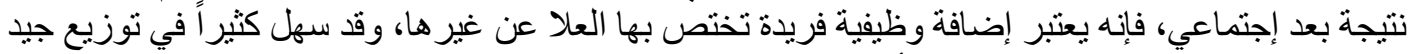

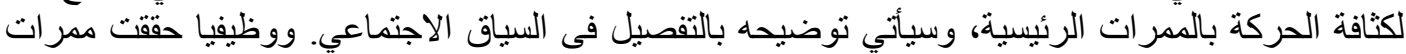

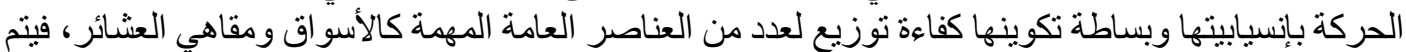

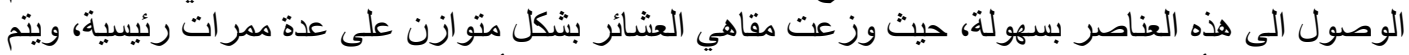

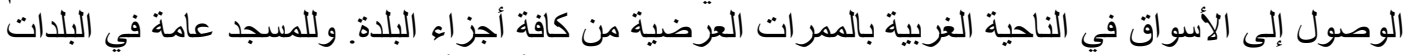

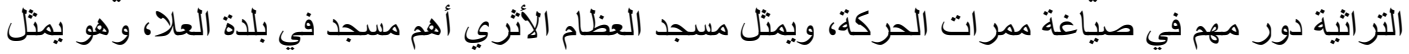

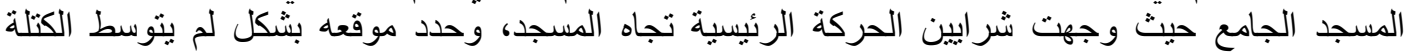

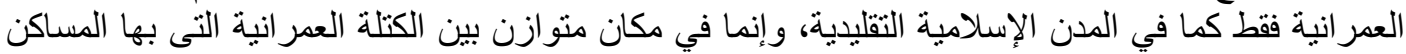
وبين المزارع التي يلّجأ إليها السكان في أوقات الحرارة الإنة الثّديدة (شكل 13). 

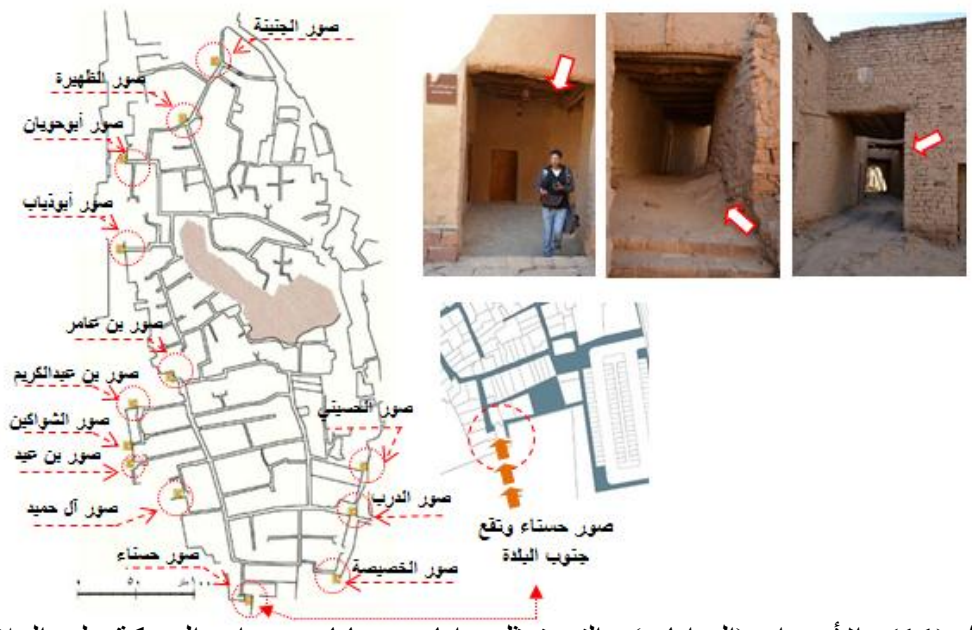

شكل (11): الأصو ار (البو ابات) و التي تمثل بدايات ونهايات ممر ات الحركة ببلدة العلا[6]، [10]

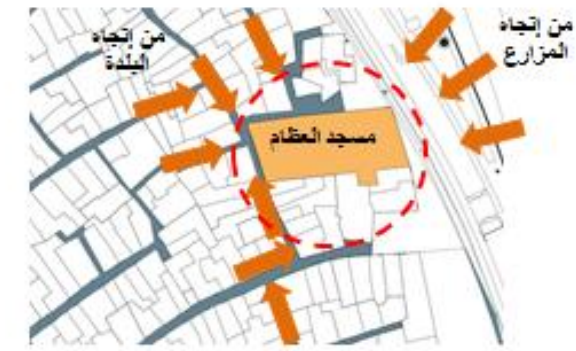

شكل (13): موقَع مسجد العظام والحركة إلبها

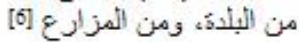

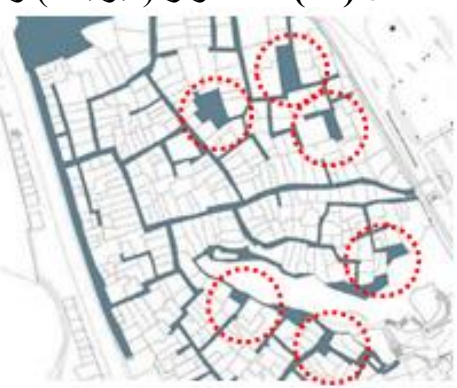

شكل (12): الساحات عند بعض الثقاطعات

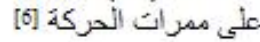

5.3. عنصر الحركة في السباق المعداري

بدراسة التصميم المعماري لمساكن العلا، لتوضيح علاقة الحركة بعناصر المسكن، نجد أن المسكن

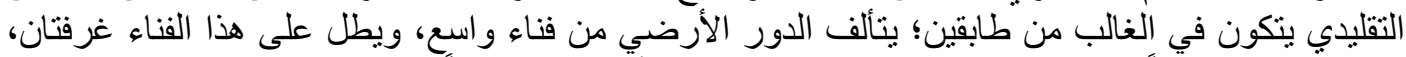

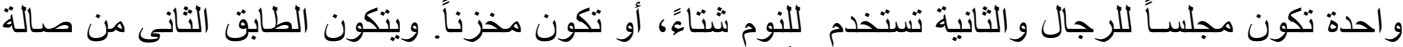

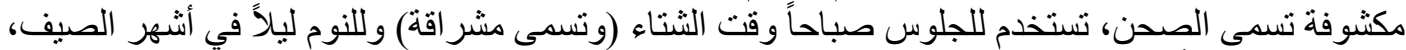

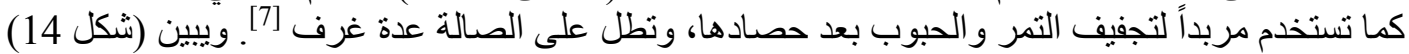

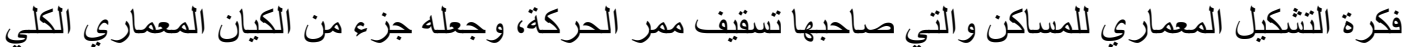

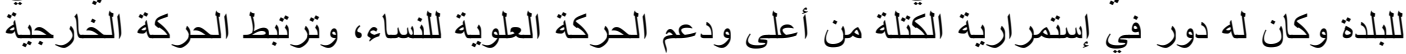

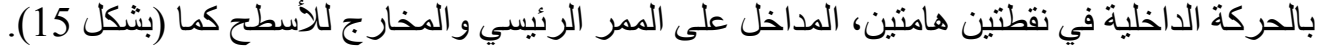
إلأرانات اعلى المدرات (الطيارة)

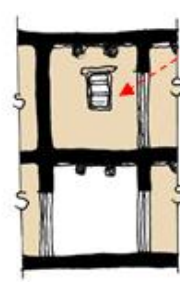

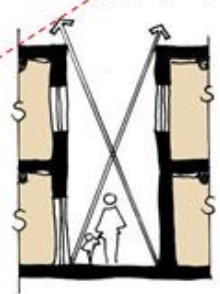

i $-i$

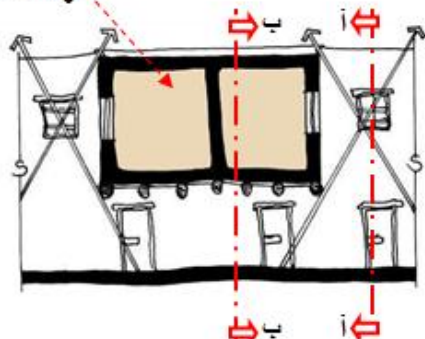

岸官

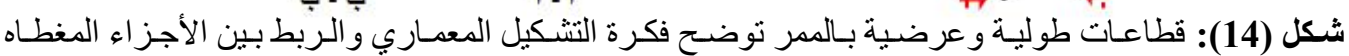

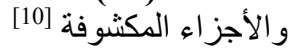




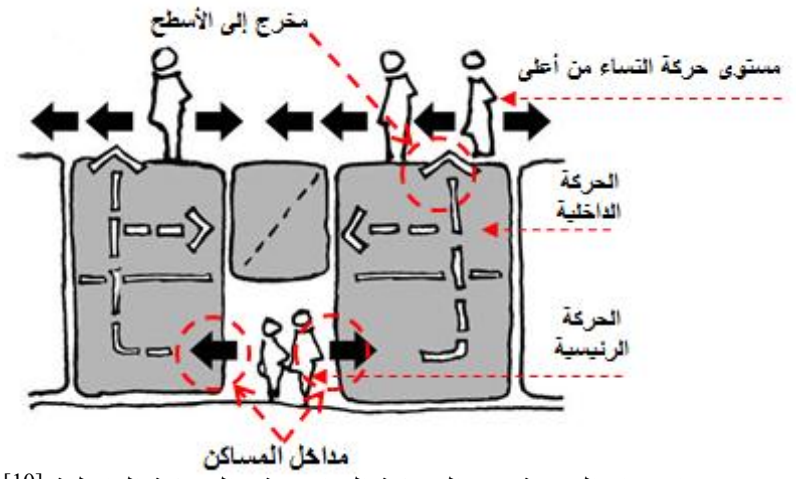

شكل (15): دايجر ام العلاقة بين الحركة الخارجية والحركة الداخلية [10]

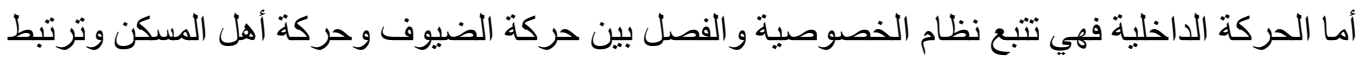

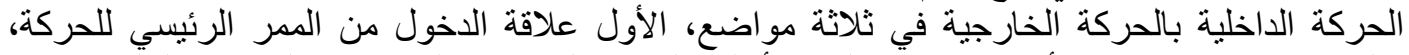

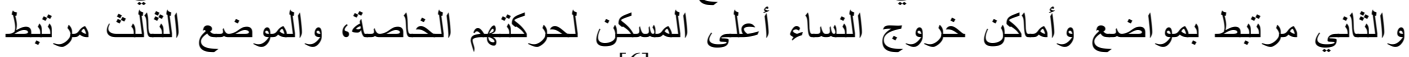

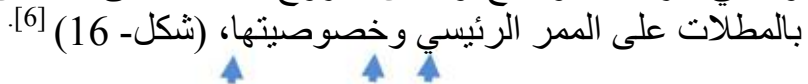
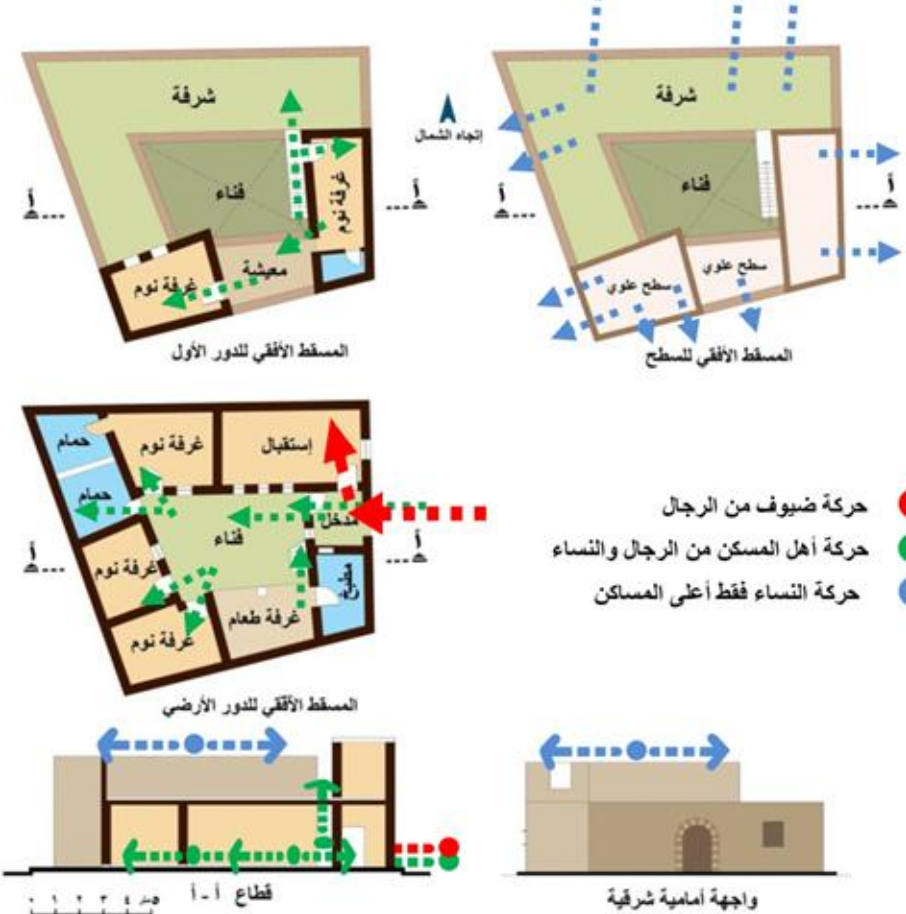

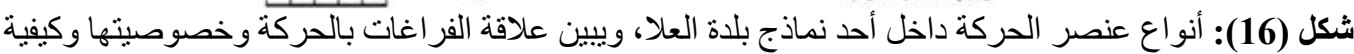

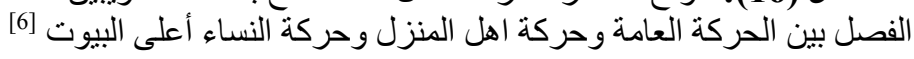

$$
\text { 6.3. عنصر الحركة في السباق الإجتماعي والأمني وحني }
$$

أدت الظروف الحياتية والمنظومة الإجتماعية القبلية التي عاثها أهل العلا عبر أطوار تاريخهم، إلى وجود

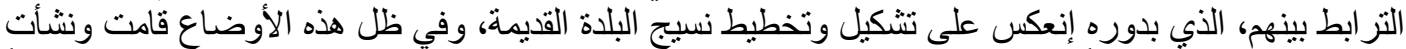

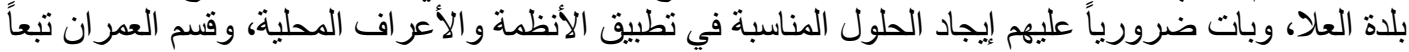

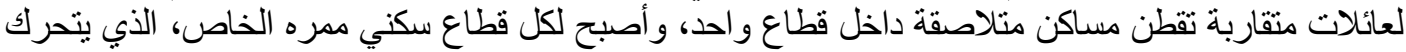


و وائل حسين بيوسف أحدد، المردود البيئي والاجتماعي والأمني على تصديم وتثكيل عناصر الدركة الخارجية في الددن.

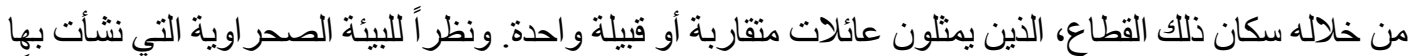

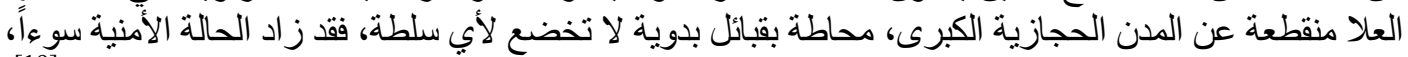

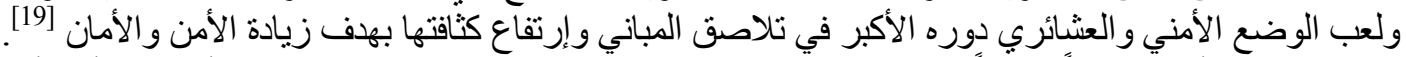

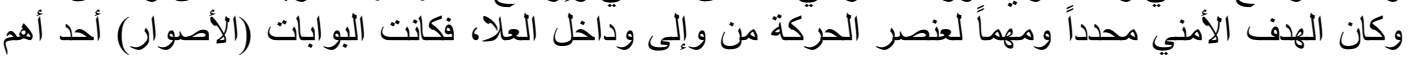

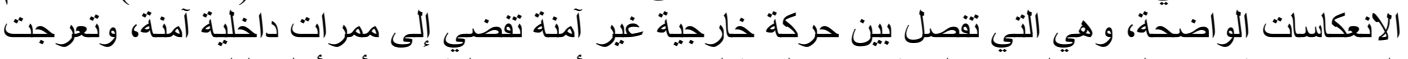

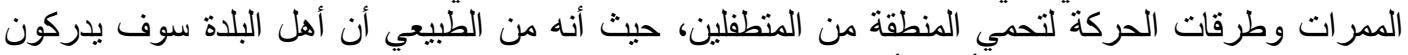

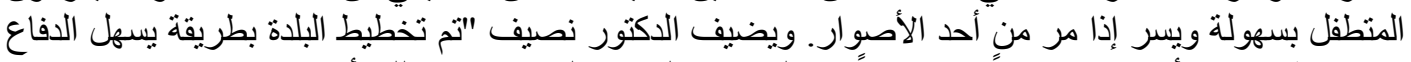

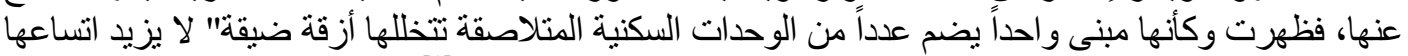

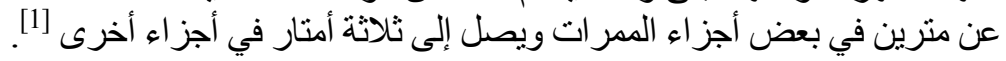

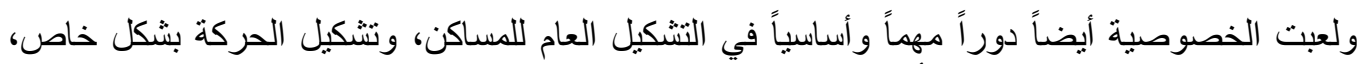

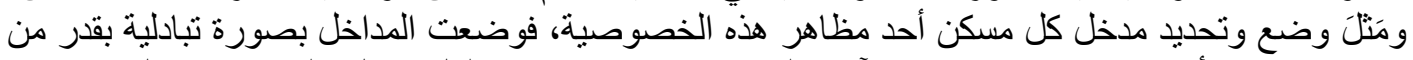
الإز احة، بحيث أنه لا يفتح بمو اجهة مسكن آخر، ليحقق خصوصنية خاصة لكل مدخل على حدة، (شكل - 17).
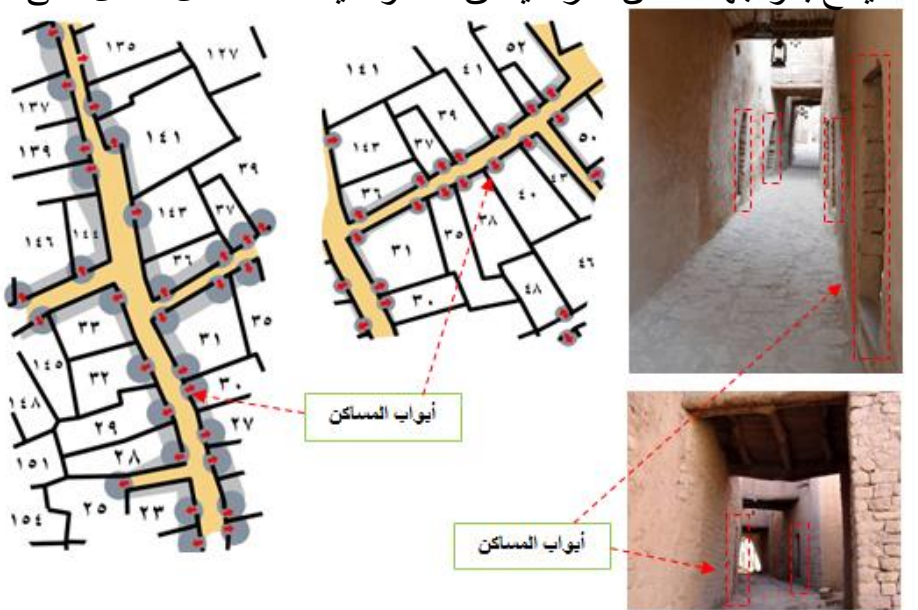

شكل (17): يوضح عدم تقابل مداخل البيوت لتحقيق مفهوم الخصوصية [10]

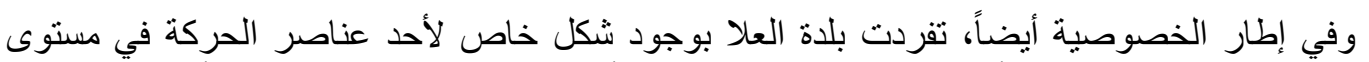

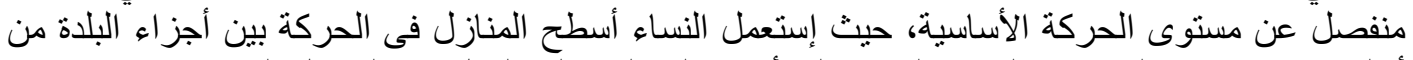

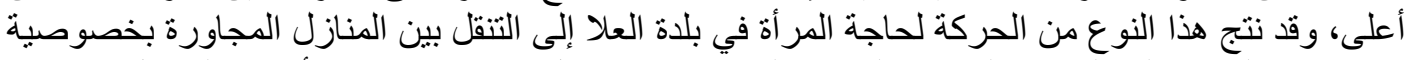

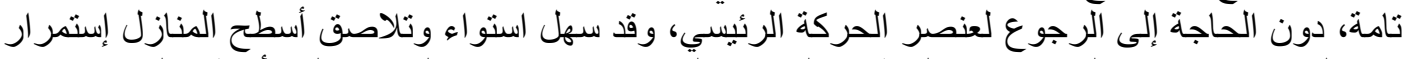

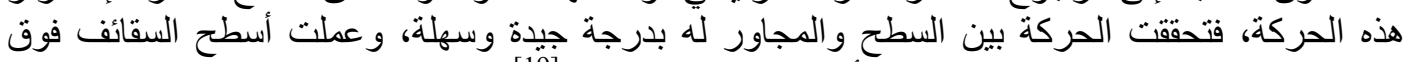

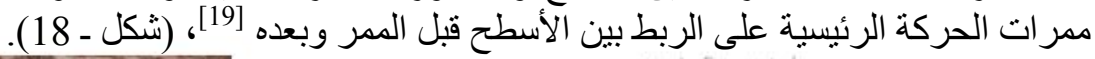
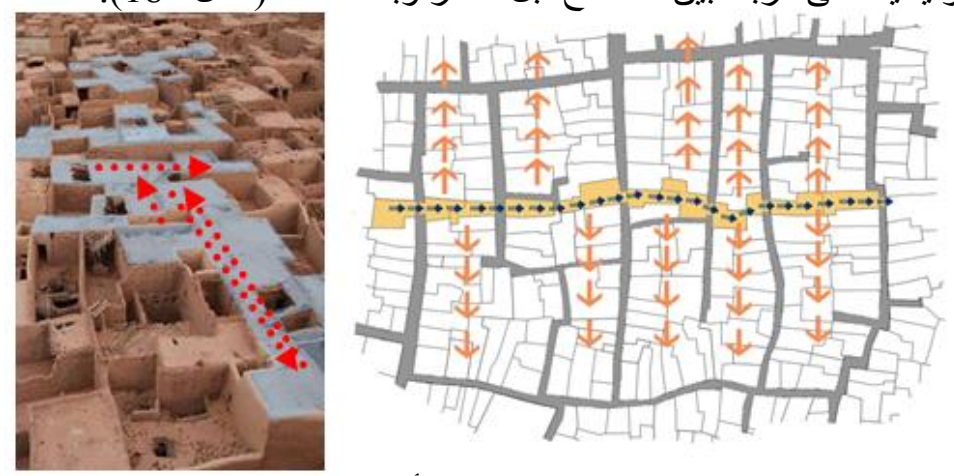

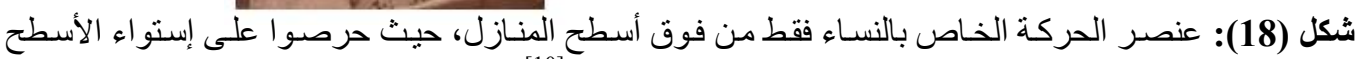

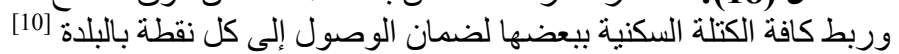


614

JES, Assiut University, Faculty of Engineering, Vol. 44, No. 5, September 2016, pp. 603 - 621

4. خلاصة المفاهيم والمؤثرات الخاصة بحالة بلدة العلا علي عنصر الحركة

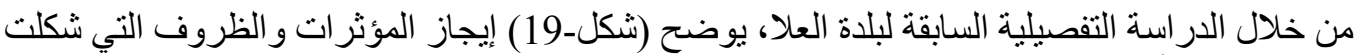

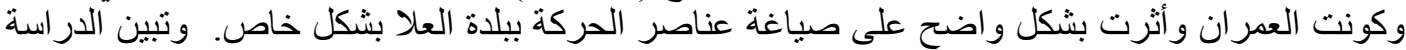

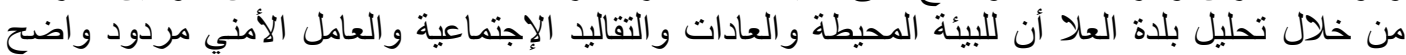

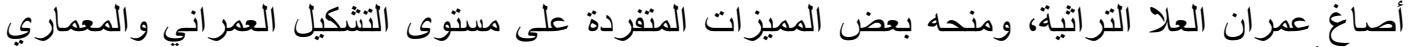

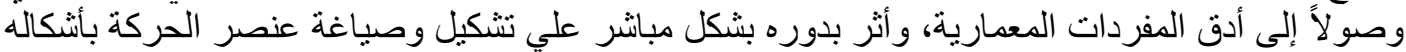
العامة و الخاصة، و أصبح ر رابط وحاكم لعناصر البلدة ولئرة وتشكيلها.
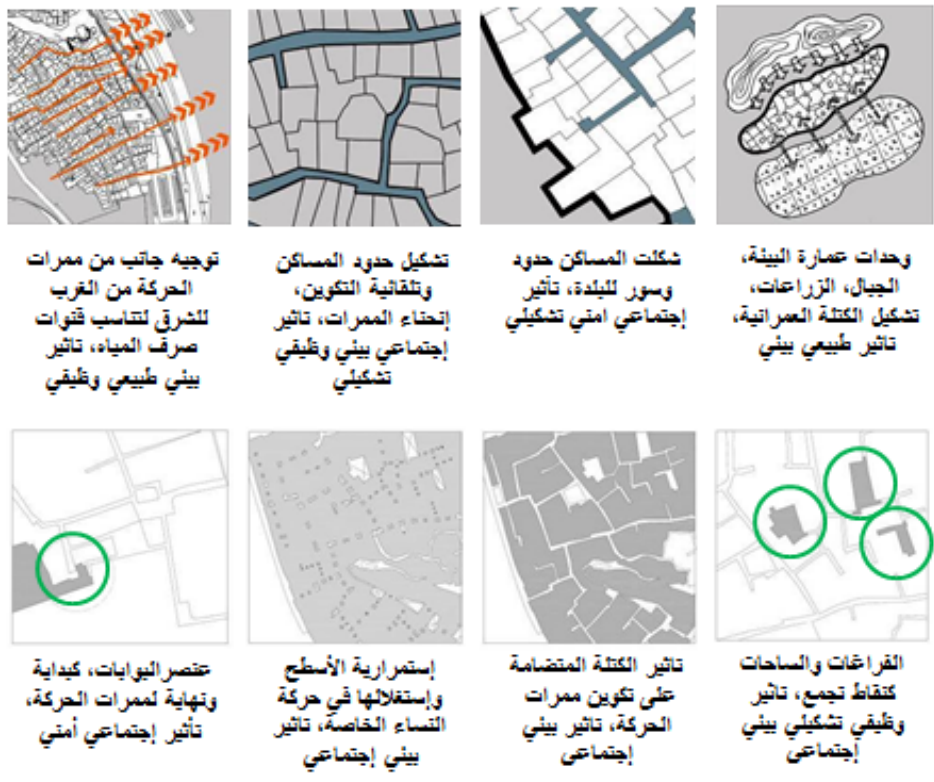

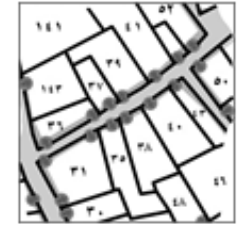

تمدم تقائل مداخل المساكن، تأثير زئيقي إجتمأعير

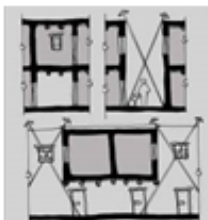

ممرات مسقرفة، حاجة

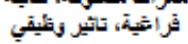
ينبي تشكيفي

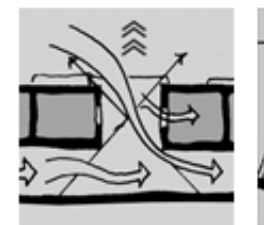

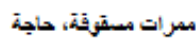

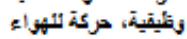

تائيز متاخي يبئي

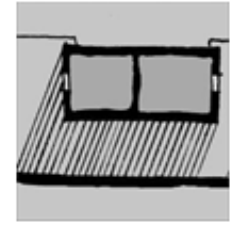

ممر ات مسقوقة، حاجة

وثئيقة، تكوين الثظالد تاثير مناخي بيني

شكل (19): خلاصة المؤثرات على تكوين عنصر الحركة ببلدة العلا التراثية [10]

5. المردود البيئي والإجتماعي والأمني، وخلاصة المفاهيم التصميمية المؤثرة علي تصميم

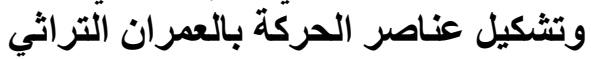

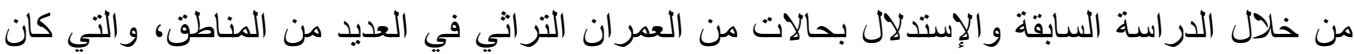

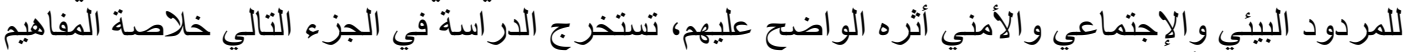

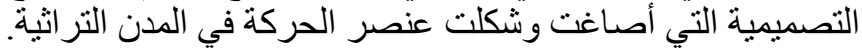

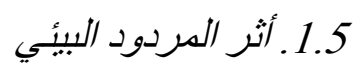

تأثر العمر ان التراني بشكل واضح بالبيئة المحيطة وظهر ذللك في العديد من المناطق التر اثية، و إنعكست التهن

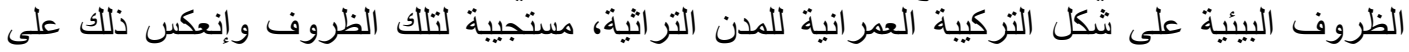

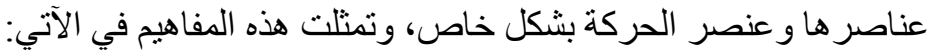




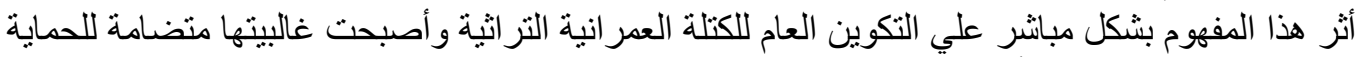

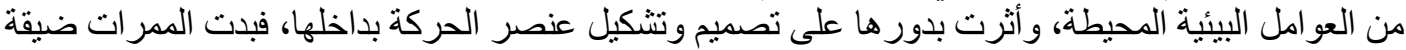

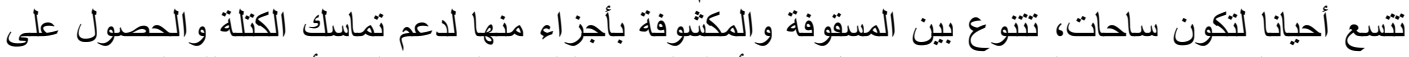

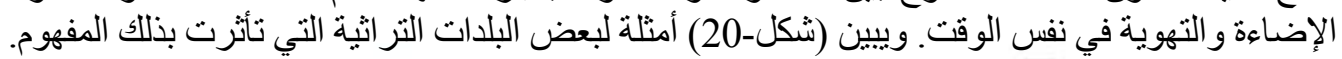
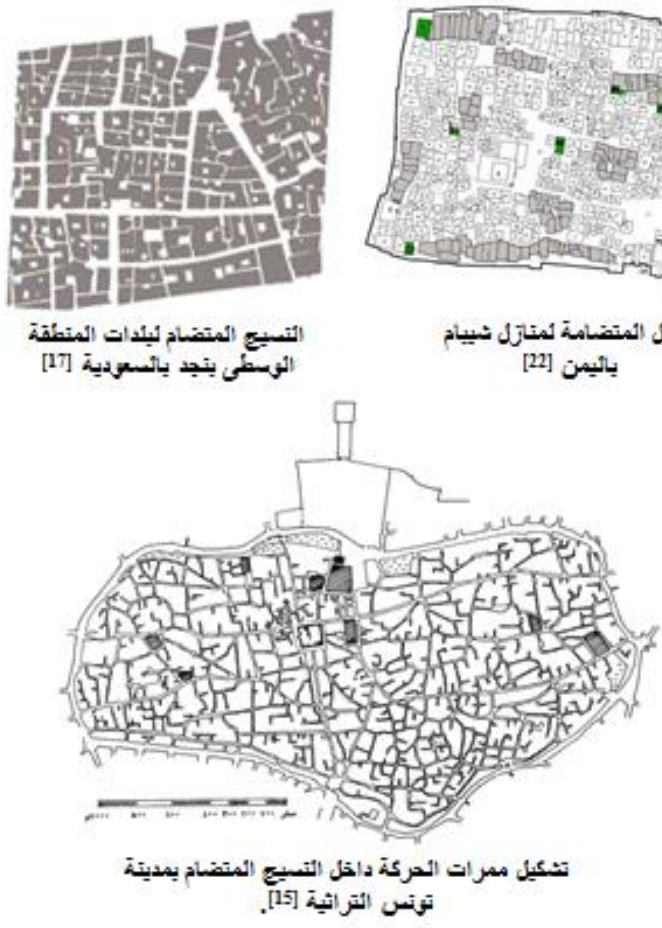

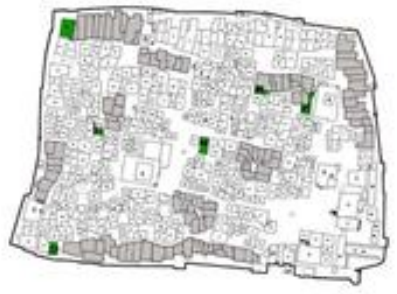

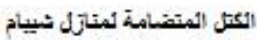

[22] بالئيمن

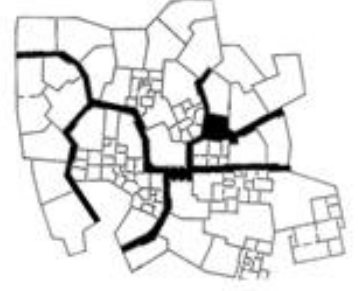

الثنكل المتضفام بكتية حي

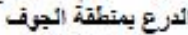

[أسبردية

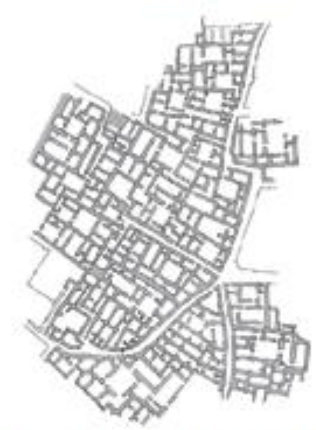

$$
\begin{aligned}
& \text { تضام العمران وتثكيل ممرات الحرية بموقيع }
\end{aligned}
$$

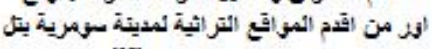

$$
\begin{aligned}
& \text { انمقير جنوي العراقي [27]. }
\end{aligned}
$$

شكل (20): أمثلة لبلدات تر اثية توضح مفهوم الحمايـة بتضـام العمر ان، و الذي بدوره منح ممر ات الحركة طابعا و سمات خاصة بين أجز اء الكتل

2.1.5. التسقبف (تظلبل، حركة رياح وتهوية، وظبفة فراغية)

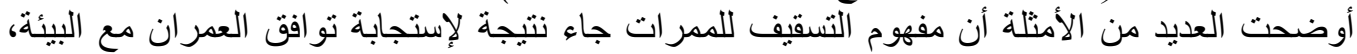

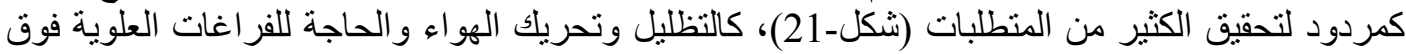
الممر ات كمنطلب وظيفي، وضمان تضام الكتلة العمر انية لتحقيق المنطلبات البيئية والمناخية. 

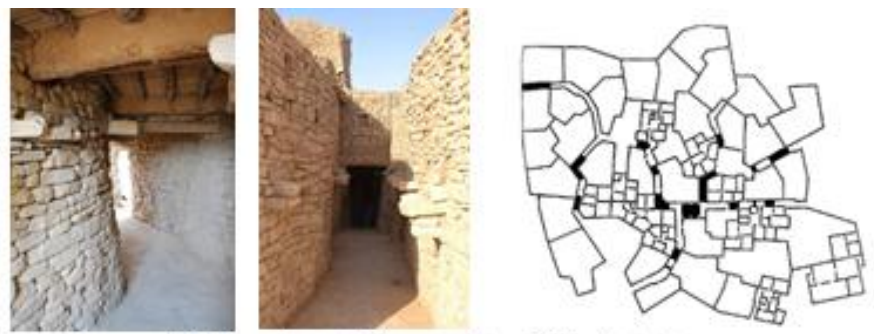

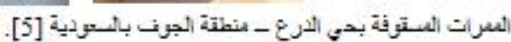
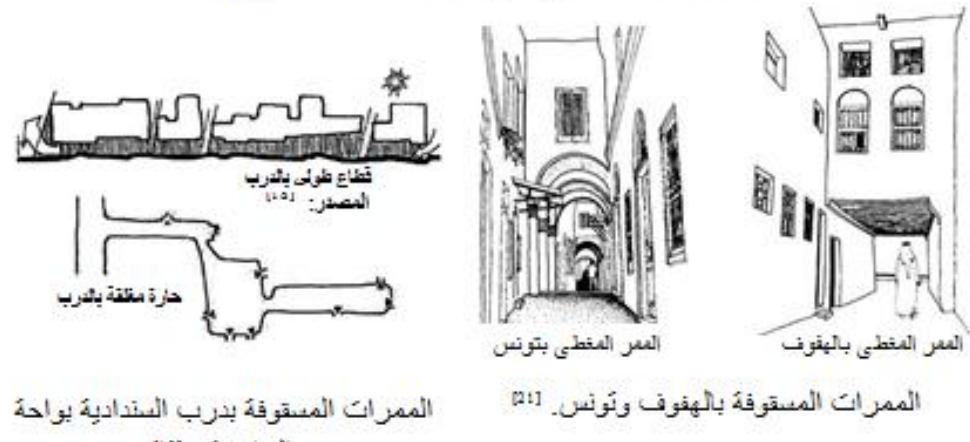

الممرات المشقوفة بالهفوق ونئوتنى.

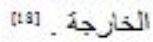

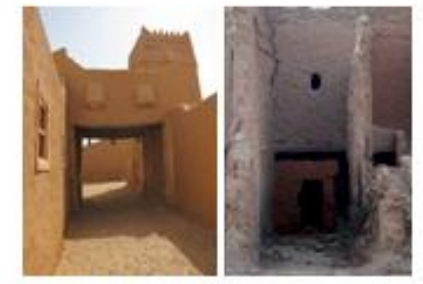

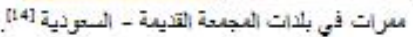

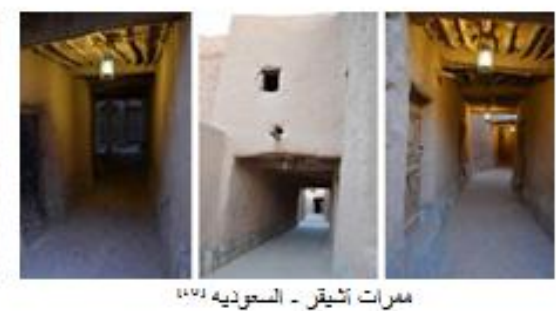

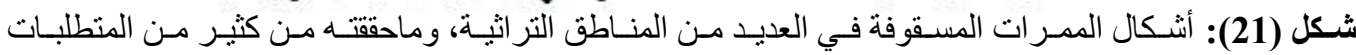
و الإحتياجات البيئية و المناخية، كالتظليل وتحريك الهو اء الرطب، و الإحتو اء

وذكر(Hkim, Basim)، "أن مفهوم تغطية الممرات يستخدم على نطاق واسع في معظم المدن العربية

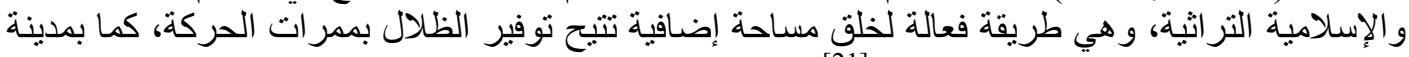

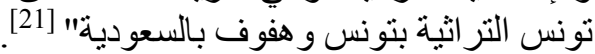

$$
\text { 2.5 أثر المردود الإجتماعي }
$$

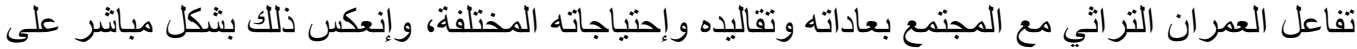

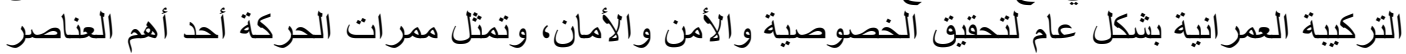

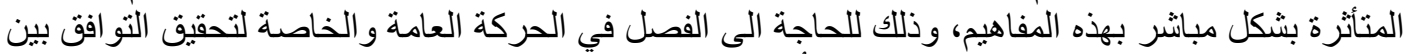

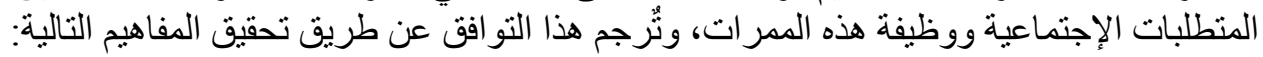

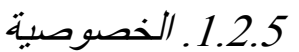

و هو أحد إنعكاسات المنظومة الإجتماعية التي تحكمها العادات و التقاليد، ويبدو ذلك واضحاً في معالجات

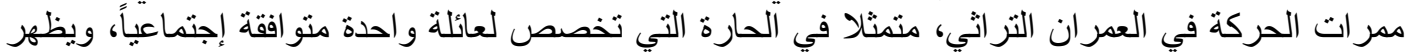

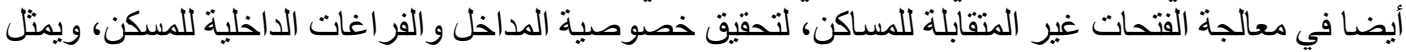

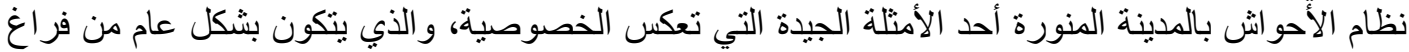

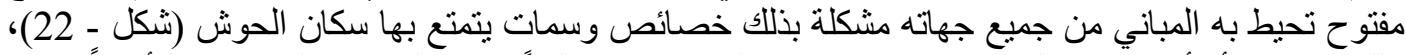
وللحوش باب أو أكثر يفتح على طريق رئيسي ومن الممكن إغلاقه ليلاً بهدف الحماية و الخصوصية أيضاً. 


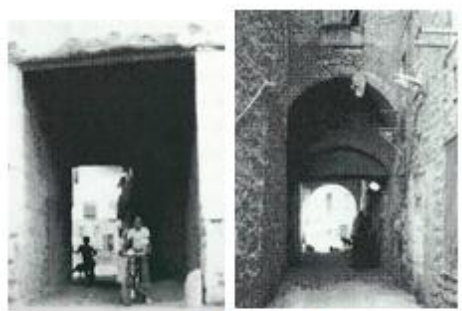

بوابات الأحراث شن شرات

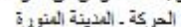

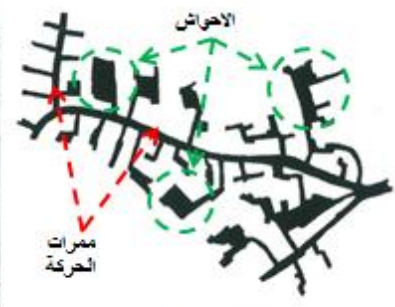

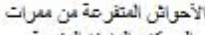

شكل (22): الأحو اشن المتقر عة من ممر ات الحركة وبو اباتها بالمدينة المنورة [4]

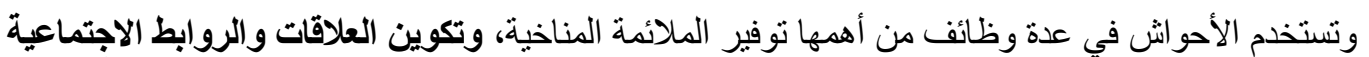

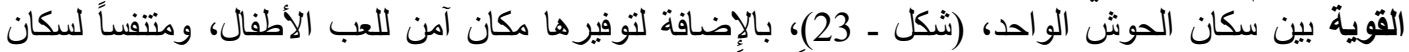

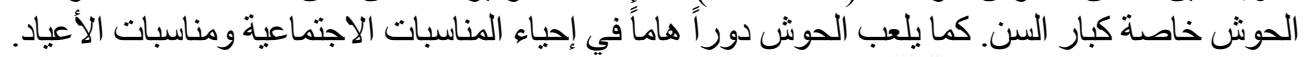

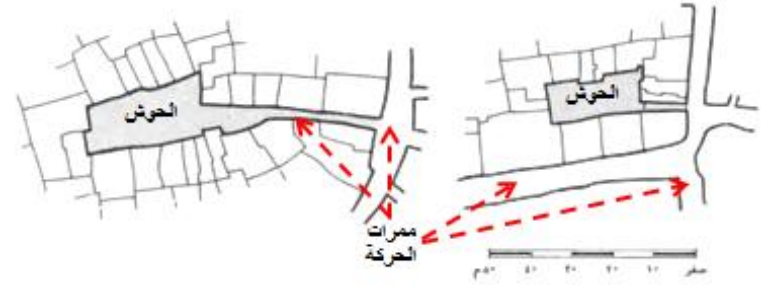

شكل (23): توفير الخصوصية في الأحواش المتفرعة من ممر ات الحركة بالمدينة المنورة [15].

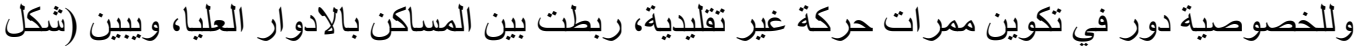

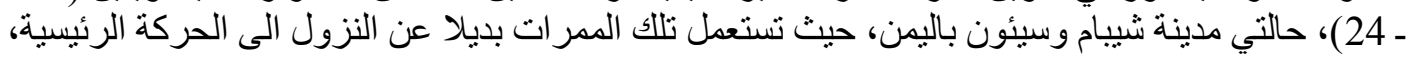

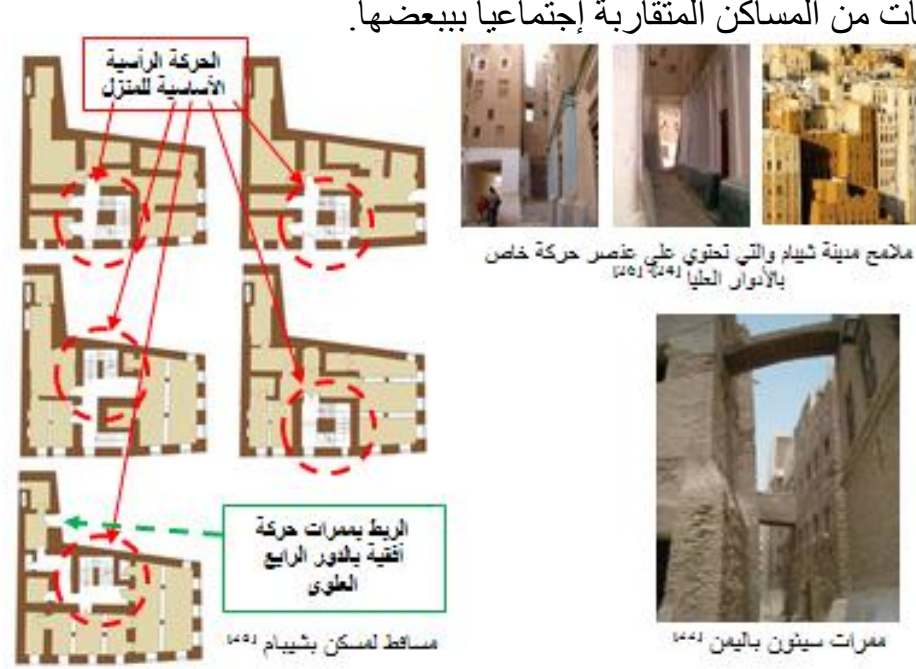

شكل (24): خصوصية ربط المساكن ببعضها في الأدوار العليا بمدينتي شيبام وسيئون باليمن

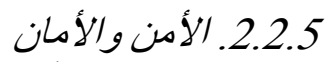

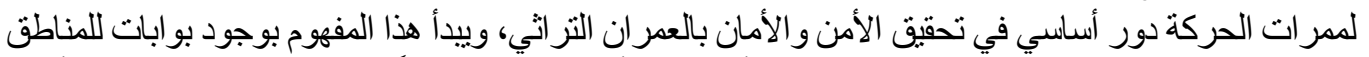

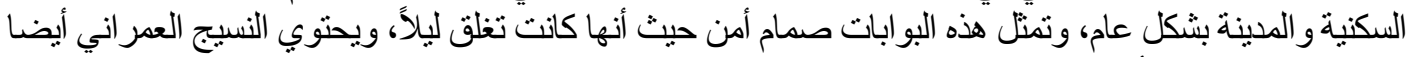

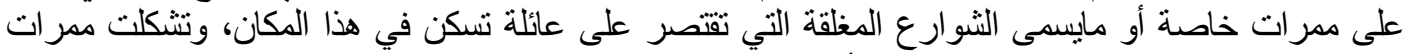
الحركة بصورة متعرجة ومنحنية في غالبية الأحيان لتحقق حركة بطيئة في حالة وجود غربة فياء لتسكل مر اقتبتهم، وذكر 
618

JES, Assiut University, Faculty of Engineering, Vol. 44, No. 5, September 2016, pp. 603 - 621

جميل أكبر بكتابه عمارة الأرض في الإسلام واصفاً ممرات الحركة "أن البيئة التقليدية بالعالم الإسلامي كان بها

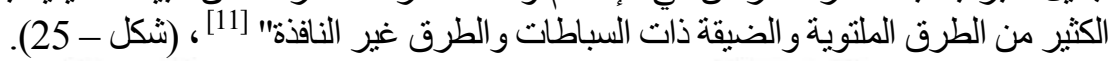

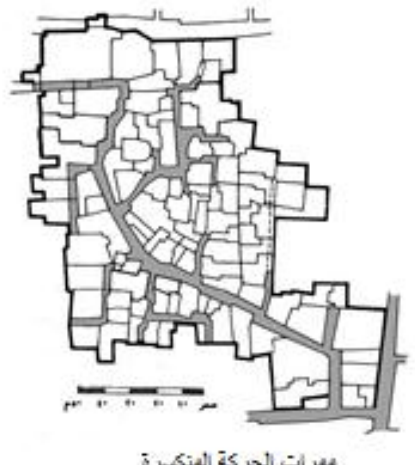

سرات الحركة المنكسرة

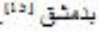

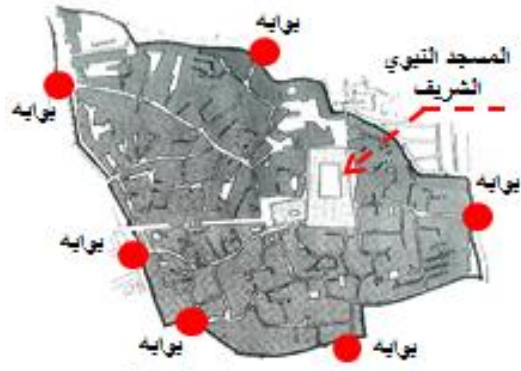

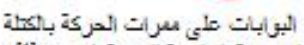

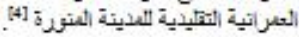

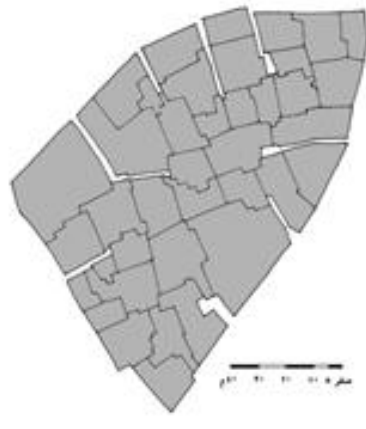

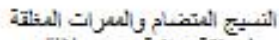

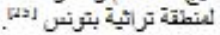

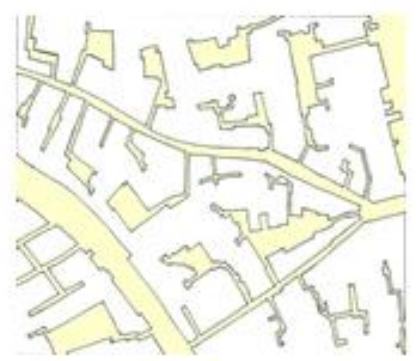

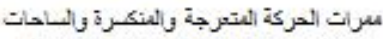

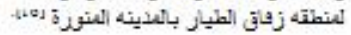

شكل (25): أشكال تأثر

6 6 ـ إستنتاجات الدراسة

1.6. إستنتاجات خاصة بيلدة العلا التراثية

مثلت بلدة العلا حالة تر اثية فريدة في تشكيل عمر انها و الطبيعة المحيطة بها، فتعددت وحدات البئية

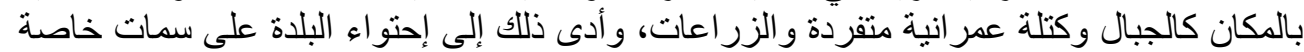

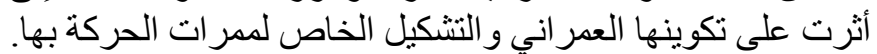

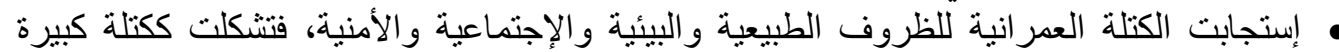

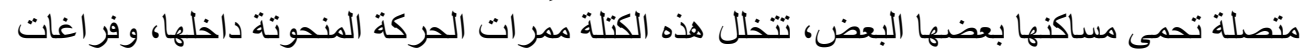

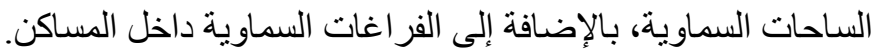

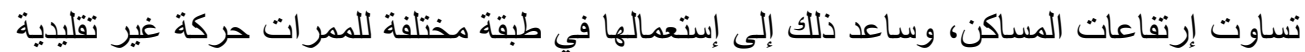

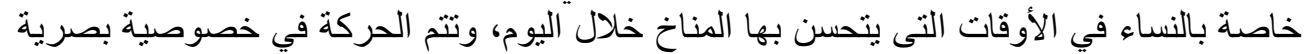

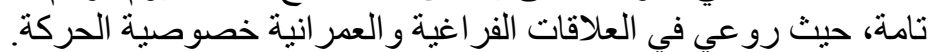

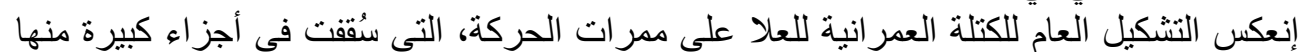

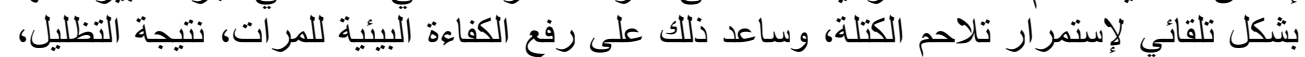

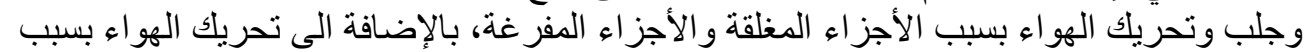

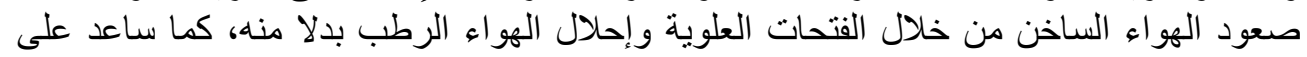
تحسين المناخ إستخدام مو اد البناء المحلية من الطين والفي الحجر. 
للعامل الأمي دور هام في صباغة ممرات الحركة فتراوحت عروضها من 2 إلى 3 أمتار تبعاً

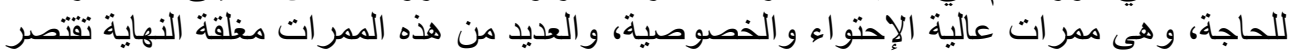

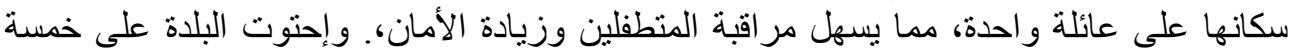
عثر بوابة، ببداية ونهاية ممر ات اتلة الحركة الرئيسية.

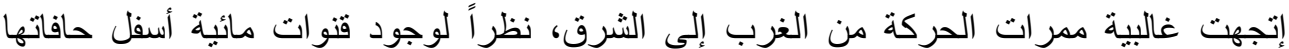

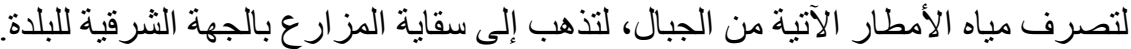

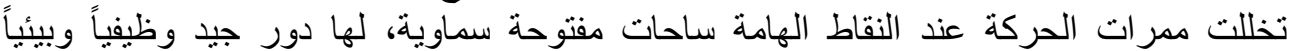

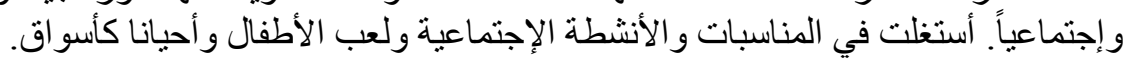

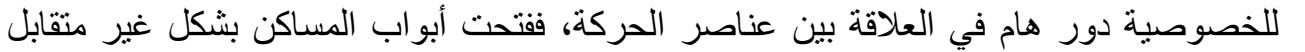

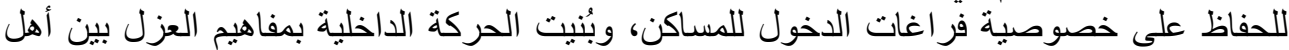

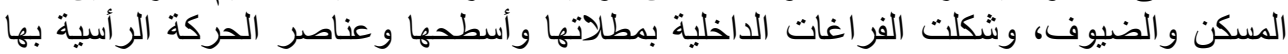

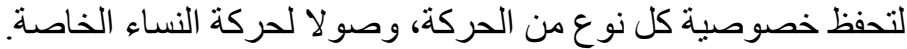

2.6. إستنتاجات عامة لعنصر الحركة ودوره كمفرد حاكم لتشكبل وصباغة العدران التراثي

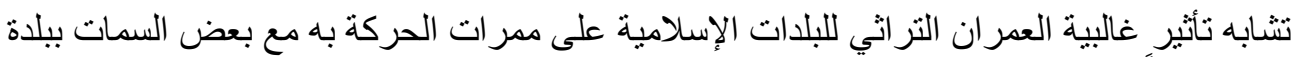

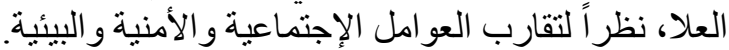

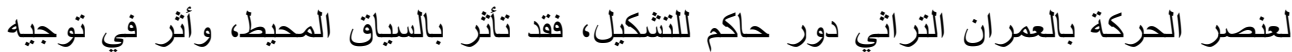

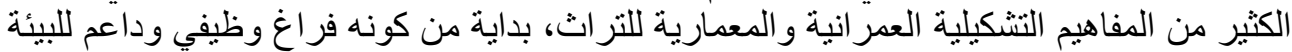

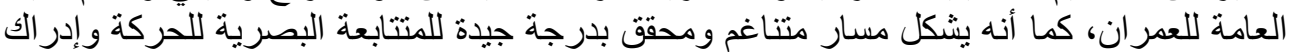

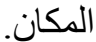

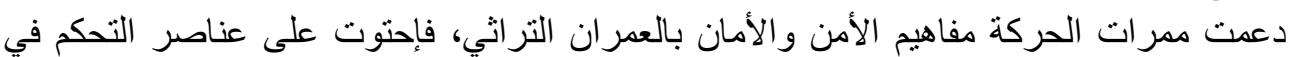

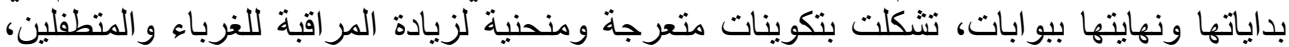

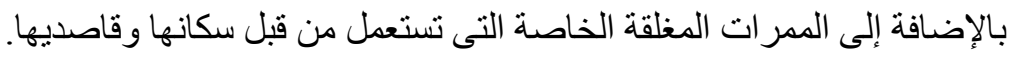

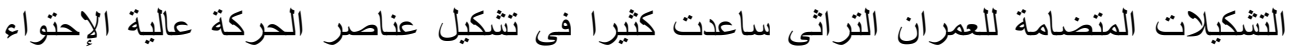

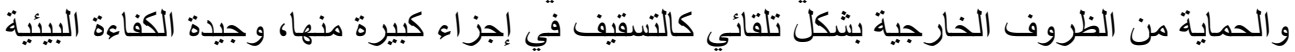
والمناخية فهي وليدة التلاحم بين الأجزاء العزية العمر انية.

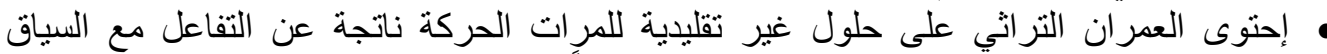

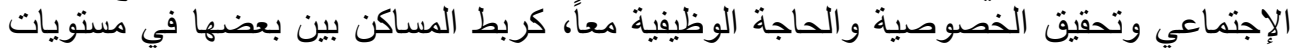
مختلفة عن ممر الحركة الرئيسي، و إستخدام الأسطح للحركة كما في بلدة العة العلا. توصي الدراسة بالتأكيد على ربط العمارة المعاصرة بالسياق المحلي الطبيعي و البيئي و الإجتماعي لتقليل الفجوة

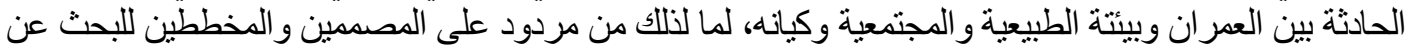

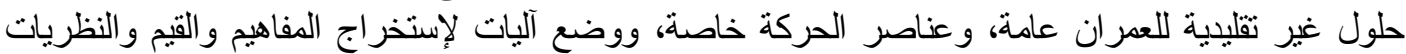

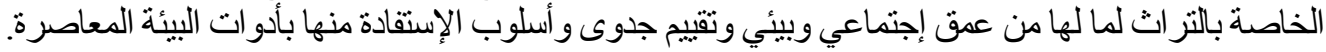

المراجع

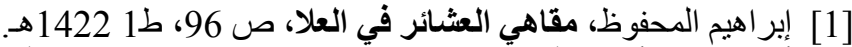

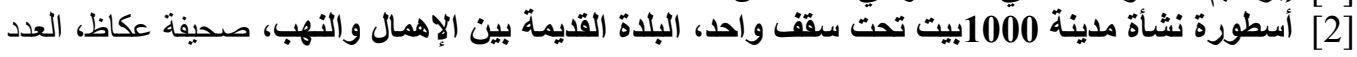

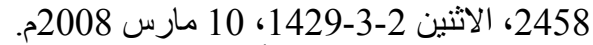

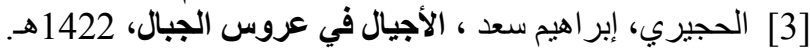

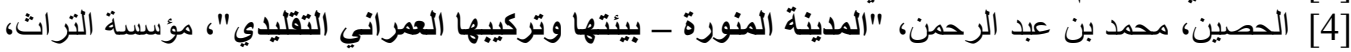
الرياض، المملكة العربية السعودية، رقم الإيداع: 1430/3089، 1431 هـهـ

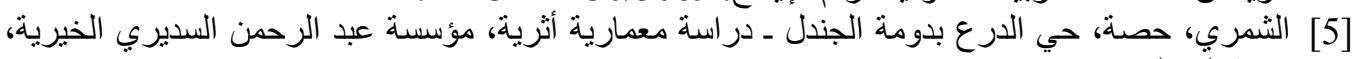


[6] العيئة العامة للسياحة والآثار، مشروع تطوير وتأهيل بلاة العلا، ملخص الوضع الراهن وبدائل المخطط

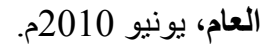

[7] أوتينج، يوليوس، رحلة داخل الجزيرة العربية، ترجمة سعيد فايز السعيد، الرياض، دارة الملك عبد العزيز،

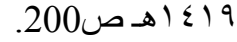

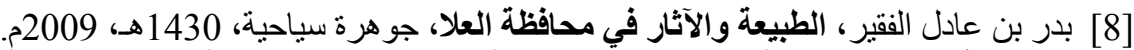

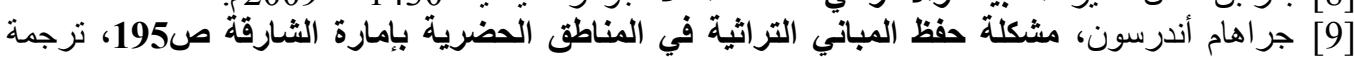

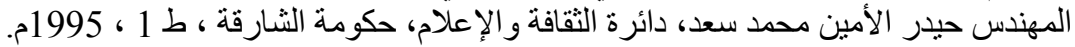

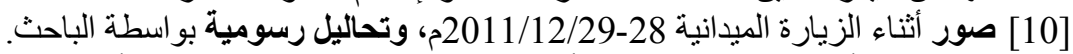
[11] عبد القادر أكبر، جميل، عمارة الثبان الأرض في الإسلام، مقارنة الثريعة بأنظمة العمران، مؤسسة الرسالة،

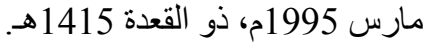

[12] عبداله النويصر، 19 محمد، خصائص التراث العدة العمراني في المملكة العربية السعودية، منطقة نجد، دارة الملك

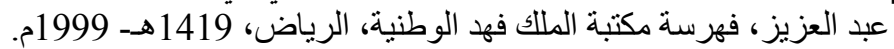

[13] عبد الستار عثمان، محمد، المدينة الإسلامية، عالمية عالم المعرفة، المجلس الوطني للتقافة و الفنون والآداب،

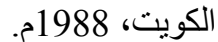

[14]عماد نور الدين، محمد، مرتضى، د.هشام: تقرير "توثيق التراث المعماري في المملكة العربية السعودية،

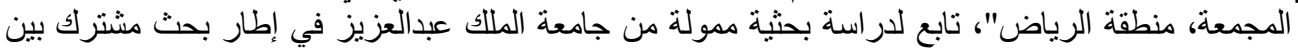

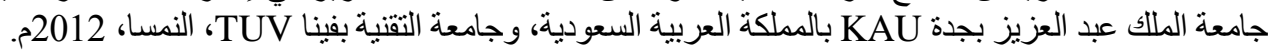

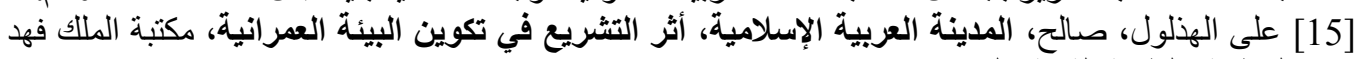

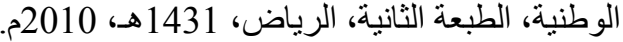

[16] كعكي، عبد العزيز بن عبد الرحمن، "النسيج العمراني للمدينة المنورة ـ الخصائص والمقومات"، مطابع

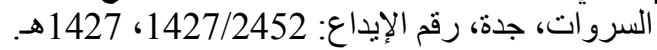

[17] وزارة الشئون البلدية والقروية، التراثة التراث العمراني في المملكة العربية السعودية بين الأصالة والمعاصرة،

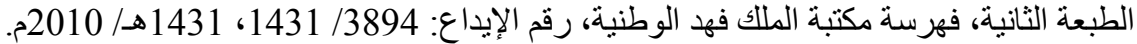

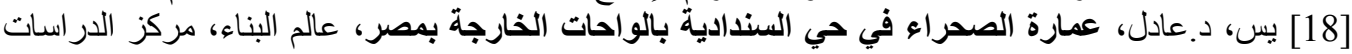

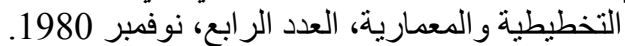

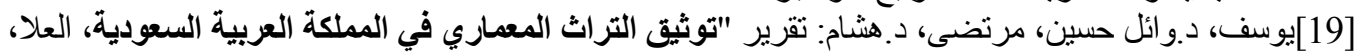

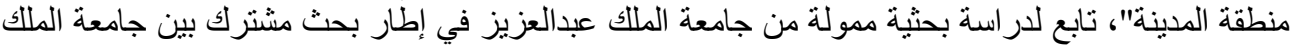

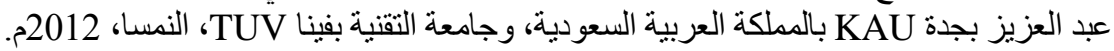

[20] Geoffrey King, The Traditional Architecture of Saudi Arabia, I.B.Tauris Publishers, London- New York, 1998.

[21] Hakim, Besim S., Generative processes for revitalizing historic towns or heritage districts, Albuquerque, New Mexico, USA, 2007.

[22] Inventory of Cultural Heritage Priority Sites, Wadi Hadramaut Cultural Atlas, MINISTRY OF CULTURE Republic of Yemen, 2002.

[23] Lechner, Norbert., Heating, Cooling, Lighting: Design Methods for Architects, John Wiley \& Sons, Inc. (US)

[24]Lehmann, Manuela, Skylines, Bridges and Mud in the Delta and elsewhere. A comparison of Egyptian and Yemeni Tower Houses, Delta Survey Workshop, British Council, Cairo, March, 2013.

[25] Lezin, Deus Villes d Ifriqiya, Paris, 1971

[26] Notes on the Geography of Yemen: Shibam (http://www.greatmirror.com/index.cfm?navid=1183), موقع على الثبكة العالمية للمعلومات

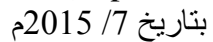

[27] Thomas, Randall.; Garnham, Trevor, Environments of Architecture :Environmental Design in Context, Taylor \& Francis Routledge, 2007.

[28] UNESCO, Old walled City of Shibam, December 22, 2011, in Architecture, Cities. 
وائل حسين يوسف أحدد، المردود البيئي والاجتماعي والأني على تصميم وتثكبل عناصر الحركة الخارجية في الددن .........

\title{
THE REFLECTION OF ENVIRONMENTAL AND SOCIAL ASPECTS ON THE DESIGN AND FORMATION OF OUTDOOR CIRCULATION ELEMENTS IN HERITAGE TOWNS CASE STUDY: AL-ULA HERITAGE TOWN - KINGDOM OF SAUDI ARABIA
}

\begin{abstract}
The research discusses the possibility to benefit from heritage concepts rooted in ancient urban areas, with all its values which were a true and expressive interaction between the environment and its human, social, natural, climatic characteristics. The circulation issue in architecture and urbanism is currently referring only to functional concept, ignoring many natural, social factors of the surrounding context. Many of rich treatments that characterized the heritage urbanism are now absent. Trying to get benefit from these values and concepts; this research deals with the outdoor circulation elements in particular.

The research aims to draw design concepts rooted in outdoor circulation elements in heritage urbanism, and their role as a governing element to forming and formulating both the architecture and urbanism, and as an active partner in the environmental system.

The town of Al-Ula in the Kingdom of Saudi Arabia has been chosen as a case study, where the majority of its urban elements have been preserved. Al-Ula represents the ancient heritage, it is characterized by its clear interaction with the surrounding context and the existence of a unique and unconventional circulation element only dedicated to women. The research also reviews other unconventional circulation elements in several heritage urban bodies in some similar areas also affected by surrounding context.

The research is divided into five parts: the first part addresses the unique form of Al-Ula town, and how it was affected and interacted with the natural, environmental, and social context of the area, and how this form influenced the forming of the circulation elements within the town. The second part studies circulation elements in Al-Ula town, draws the factors that governed these elements through the urban and architectural content, and how it was affected by other functional, environmental, and cultural contents, human and social relationships in the town body.

The third part discusses some unconventional outdoor circulation elements in similar examples in different towns and areas. The fourth part contains the most important comparisons and observations about the ancient and modern circulation elements.

The research sums up a group of important points and concepts that had a reflection on formulating the outdoor circulation elements through their spontaneous interaction with environment and community.
\end{abstract}

Keywords: Heritage - circulation elements - Social aspects - Environmental aspects - Al-Ula 